\title{
Termodinâmica clássica ou termodinâmica do equilíbrio: aspectos conceituais básicos
}

\section{Classical or equilibrium thermodynamics: basic conceptual aspects}

\author{
Antonio Braz de Pádua ${ }^{1}$; Cléia Guiotti de Pádua ${ }^{2}$; João Lucas Correia Silva ${ }^{3}$; \\ Ricardo Spagnuolo Martins ${ }^{3}$; Felipe Barreiro Postali³; Luiz Augusto Calvo Tiritan ${ }^{3}$
}

\section{Resumo}

\begin{abstract}
A Termodinâmica Clássica ou Termodinâmica do Equilíbrio é uma das áreas da Física mais bem consolidadas. É sintetizada por uma estrutura de conhecimento bem definida e autocoerente. A essência da estrutura teórica da Termodinâmica Clássica está num um conjunto de leis naturais que governam o comportamento de sistemas físicos macroscópicos. Essas leis foram formuladas a partir de generalizações de observações e são, em grande parte, independentes de quaisquer hipóteses relativas à natureza microscópica da matéria. Em geral, as aproximações estabelecidas para a Termodinâmica Clássica seguem uma das duas alternativas: a aproximação histórica que faz uma descrição cronológica da evolução das idéias, conceitos e fatos e, a aproximação postulatória, na qual são formulados postulados não demonstrados "a priori", mas que podem ter suas veracidades confirmadas "a posteriori". Neste trabalho, elaboramos uma breve revisão da evolução conceitual da aproximação histórica préclássica que vai desde o início do século XVII até meados do século XIX. Para isso, abordamos de forma evolucionária e fenomenológica os seguintes temas: natureza do calor, termometria, calorimetria, máquina térmica de Carnot, equivalente mecânico do calor e, a primeira e a segunda lei. A lei zero, que foi formulada posteriormente, está incluída na discussão.

Palavras-chave: Leis da Termodinâmica. Temperatura. Equilíbrio térmico. Calor. Calórico. Máquina térmica. Ciclo de Carnot. Energia interna. Trabalho mecânico. Equivalente mecânico do calor. Entropia.
\end{abstract}

\begin{abstract}
The Classical or Equilibrium Thermodynamics is one of the most consolidated fields of Physics. It is synthesized by a well-known and self coherent knowledge structure. The essence of the Classical Thermodynamics theoretical structure consists of a set of natural laws that rule the macroscopic physical systems behavior. These laws were formulated based on observations generalizations and are mostly independent of any hypotheses concerning the microscopic nature of the matter. In general, the approaches established for the Classical Thermodynamics follow one of the following alternatives: the historical approach that describes chronologically the evolution of ideas, concepts and facts, and the postulational approach in which postulates are formulated but are not demonstrated a priori but can be confirmed a posteriori. In this work, a brief review of the pre-classical historical approach conceptual evolution is elaborated, from the beginning of the seventeenth century to the middle of the nineteenth century. As for this, the following themes are dealt with in an evolutionary and phenomenological way:
\end{abstract}

\footnotetext{
1 Doutor em Física, Professor Associado C, Departamento de Física, Centro de Ciências Exatas, Universidade Estadual de Londrina. E-mail: padua@uel.br.

2 Mestre em Física, Professor Adjunto D, Departamento de Física, Centro de Ciências Exatas, Universidade Estadual de Londrina, Londrina, PR

3 Alunos de Graduação em Física, Departamento de Física, Centro de Ciências Exatas, Universidade Estadual de Londrina, Londrina, PR.
} 
heat nature, thermometry, calorimetry, Carnot's heat engine, heat mechanical equivalent and the first and second laws. The Zeroth law that was formulated afterwards is included in the discussion.

Key words: Thermodynamics laws. Temperature. Thermal equilibrium. Heat. Caloric. Heat engine. Carnot's Cycle. Internal energy. Mechanical work. Heat mechanical equivalent. Entropy.

\section{Uma síntese da evolução conceitual}

Para o físico, a Termodinâmica Clássica ou Termodinâmica do Equilíbrio é uma das poucas áreas bem consolidadas da Física, sintetizada por uma estrutura de conhecimento bem definida e autoconsistente. A essência da estrutura teórica da Termodinâmica Clássica é um conjunto de leis naturais que governam o comportamento de sistemas físicos macroscópicos. As leis foram derivadas de generalizações de observações experimentais e são, em grande parte, independentes de quaisquer hipóteses relativas à natureza microscópica da matéria (CALLEN, 1985; KONDEPUDI; PRIGOGINE, 1999; MODELL; REID, 1974; PÁDUA; PÁDUA, 2006; SOMMERFELD, 1964).

Quase todas as aproximações estabelecidas para a Termodinâmica Clássica seguem uma das duas alternativas: a aproximação histórica, que faz um estreito paralelo entre a evolução cronológica dos conceitos corretos e dos falsos juízos e, a aproximação postulatória, na qual são formulados postulados que não são demonstrados "a priori", mas que podem ter suas veracidades confirmadas “a posteriori”. Há méritos e desvantagens em cada uma dessas aproximações.

A aproximação histórica, como já dissemos, tem uma base fundamentalmente empírica e foi desenvolvida ao longo de um período que durou mais ou menos 250 anos, que vai desde o início do século XVII até os meados do século XIX. Os adeptos da aproximação histórica defendem que, se esperamos que nossos estudantes compreendam bem os fundamentos da Termodinâmica e, a partir deles, possam formular novos conceitos e teorias, devemos expor a eles o desenvolvimento histórico das teorias existentes. Após o parágrafo seguinte, descreveremos os aspectos gerais dessa aproximação.
As primeiras idéias de se estabelecer uma aproximação postulacional ou axiomática para a Termodinâmica foram apresentadas no início do século XX por alguns matemáticos seguidores da escola formalista. Entre eles, podemos mencionar o matemático francês Jules Henri Poincaré (1854 1912), que levantou questões acerca das definições de temperatura e calor e dos enunciados das duas leis da Termodinâmica, e, principalmente, o matemático grego Constantin Carathéodory (1873 - 1950), que, em 1909, publicou um trabalho pioneiro, no qual propôs uma estrutura formal lógica alternativa para a Termodinâmica. Depois deste, elaboraram-se muitas outras propostas de axiomatizações da Termodinâmica (KONDEPUDI; PRIGOGINE, 1999; MODELL; REID, 1974). No texto da referência número 8 , nós discutimos esse assunto, e damos um realce especial à proposta do físico húngaro Laszlo Tisza, concebida na década de 1940 e estruturada por Herbert Callen em 1960 (CALLEN, 1985). As aproximações postulatórias existentes, em geral, não fazem nenhuma referência aos desenvolvimentos históricos.

$\mathrm{Na}$ aproximação histórica, podemos citar os seguintes assuntos que formam o arcabouço da evolução basal da Termodinâmica: termometria, calorimetria, natureza do calor, máquina a vapor, equivalente mecânico do calor, e a primeira e a segunda lei. A lei zero e a terceira lei foram formuladas posteriormente.

Como mencionamos, a origem da Termodinâmica Clássica está localizada no início do século XVII. No entanto, suas leis, tal como as conhecemos hoje, não foram formuladas até meados do século XIX. Este período de quase 250 anos é conhecido como pré - clássico, durante o qual muitos dos conceitos térmicos empregados atualmente foram desenvolvidos. 
O livro de Model e Reid (MODELL; REID, 1974) traz uma interessante síntese acerca dessa aproximação. Com algumas pequenas modificações que julgamos necessárias, transcrevemo-la integralmente da seguinte forma:

"A evolução cronológica da Termodinâmica é um exemplo fascinante de aplicação da metodologia cientifica. A experimentação em termometria conduziu ao desenvolvimento de hipóteses e conceitos como, por exemplo, escalas termométricas, pontos fixos de referência, dilatação térmica, temperatura, etc; que por sua vez, sugeriram outras experiências (no caso em calorimetria), as quais levaram a novos conceitos como, paredes adiabáticas, teoria do calórico, calor latente, etc. Os eventos históricos também ilustram algumas armadilhas na análise cientifica, tais como a supervalorização de imagens intuitivas, principalmente a respeito da natureza de calor, que muito se distanciavam das observações e fatos existentes. Enfatizamos que o período de pré - clássico foi marcado por muitas controvérsias e conflitos.

O início do periodo de pré - clássico é normalmente associado às tentativas de Galileu para quantificar a termometria, o que ocorreu por volta de 1600. É interessante notar que o cientista do século XVII era motivado principalmente por um desejo de entender os fenômenos que eram percebidos pelos seus sentidos. Em contraste, os cientistas de hoje demandam de instrumentos muito mais sensiveis e elaborados para que possam detectar fenômenos que estão muito distantes do alcance direto de seus sentidos. Um dos objetivos principais de Galileu era quantificar as experiências subjetivas do quente $e$ do frio. A expansão do ar ao aquecer foi observada na era Helenística, mas nunca foi aplicada. Galileu usou esse fenômeno no seu dispositivo constituido de um bulbo e uma haste, com a haste submersa na água. As medidas mudavam com tempo, mas no início dos anos de 1600 não havia nenhuma razão para assumir que elas não deveriam variar de tal uma maneira. Não havia até 1643, quando um estudante de Galileu, Torricelli, desenvolveu o barômetro, que com este se concluiu que o dispositivo de Galileu era mais um "barotermoscópio" do que um termômetro. Com o desenvolvimento da tecnologia de soprar vidro na época e, como conseqüência, uma melhora na capacidade de fabricação de vasos capilares estreitos, ocorreu uma grande evolução dos termômetros a líquidos nos anos de 1630. Como era de se esperar, a água foi o primeiro líquido a ser usado. Com as dificuldades experimentadas, que seriam óbvias aos estudantes de hoje, 10 anos se passaram antes que o termômetro a álcool hermeticamente fechado ganhasse aceitação. Os termômetros a gás não apareceram até os anos de 1700, quando as propriedades dos gases foram melhores compreendidas.

Quando qualquer instrumento experimental novo é desenvolvido, há invariavelmente o desejo de quantificar os resultados obtidos por meio dele, para que investigadores diferentes possam compará-los. A quantificação da termometria exigiu a introdução de pelo menos dois pontos de referência ou fixos. Paremos por um momento e reflitamos: se estivéssemos em 1640 que pontos fixos escolheríamos? O ponto de ebulição de água? Variava a cada dia. O ponto congelamento da água? Era difícil de achar gelo durante a maior parte do ano. Além disso, não havia nenhuma razão para se acreditar que materiais como água tivessem propriedades excepcionais que poderiam ser reproduziveis. Assim, é compreensivel que nossos antecessores buscassem referências fenomenológicas, tais como: a "água mais quente que a mão poderia resistir" ou o "frio do inverno mais severo" ou a "temperatura do corpo humano". Mais tarde, referencias como, o ponto de derretimento da manteiga ou o ponto de congelamento do óleo 
da semente de anis, muito embora, tenham sido passos em direção à objetividade, foram descartadas, pois a transição entre estes pontos não era muito precisa e, também porque, eles na verdade não tinham nenhum significado especial. Somente no final do século XVII e início do XVIII, os pontos de congelamento e de ebulição de água começaram a ser adotados $e$ ganharam aceitação.

Com o avanço da experimentação termométrica quantitativa, tornou-se desde cedo aparente que, tipos diferentes de recipientes tinham propriedades térmicas diferentes. Líquidos quentes esfriavam menos rapidamente em vasilhas de mica ou de madeira do que em vasilhas de metais. Estas observações conduziram ao conceito idealizado da parede adiabática que poderia ser aproximada na prática; assim, nasceu a ciência da calorimetria.

Se duas quantidades de um mesmo fluido estivessem misturadas em um calorímetro, a temperatura final poderia ser expressa como uma média ponderada das duas temperaturas iniciais:

$$
\mathrm{t}_{\mathrm{f}}=\frac{\mathrm{C}_{1} \mathrm{t}_{1}+\mathrm{C}_{2} \mathrm{t}_{2}}{\mathrm{C}_{1}+\mathrm{C}_{2}}=\frac{\mathrm{C}_{1}}{\mathrm{C}_{1}+\mathrm{C}_{2}} \mathrm{t}_{1}+\frac{\mathrm{C}_{2}}{\mathrm{C}_{1}+\mathrm{C}_{2}} \mathrm{t}_{2}
$$

O fator peso poderia ser a massa ou o volume.

Embora a equação acima tem a forma de uma lei de conservação, não está claro o que é conservado. Uma interpretação simplista seria considerar a temperatura como a quantidade conservada. À lei de conservação foi dada uma maior importância, quando na metade dos anos 1700, foi mostrado que esta equação era inválida quando líquidos diferentes eram misturados, tomando-se a massa ou volume como fatores peso. Nos anos de 1760, Joseph Black sugeriu uma modificação que era consistente com a mistura de dados para fluidos diferentes. As constantes $\mathrm{C}_{\mathrm{i}}$ desta equaçãoforam subdivididas em um componente relacionado com a massa e um parâmetro de intensidade, o calor especifico, que era uma propriedade intrínseca do líquido. Esta foi a primeira vez em que se percebeu que a matéria tinha propriedades características no sentido de um comportamento termodinâmico.

A modificação de Black indicou que, num processo de mistura, era conservada uma outra quantidade diferente da temperatura. Esta 'quantidade' ou 'grandeza' referente ao termo genérico calor, foi chamada de calórico. Certamente, a interpretação do que era realmente este calórico, foi além das observações fisicas e adentrou no reino da metafísica. A teoria do calórico tentou definir a natureza microscópica da quantidade conservada.

A hipótese ingênua de Black levou a uma onda de experimentação durante a qual os calores especificos foram medidos e os resultados informados às sociedades reais florescentes. A lei de conservação foi repetidamente desafiada, mas através de experimentações mais exatas, a teoria foi ampliada para levar em conta a variação de calor específico com temperatura e, posteriormente, foram introduzidos os calores latentes para responder pelas transições de fase.

Nos anos de 1790, não mais que 20 anos depois do trabalho de Black, o Conde de Rumford conduziu suas exaustivas experiências para mostrar que o trabalho mecânico era uma fonte inesgotável de calórico. Conseqüentemente, o calórico não podia ser conservado e não podia ter uma natureza material. Rumford sugeriu o ressurgimento do conceito mecânico do calor, que tinha sido pensado por Newton no inicio do século e analisado por Bernoulli no final da década de 1730 e, que estava abandonado há mais de 50 anos. Embora nós saibamos agora que a sugestão de Rumford era a mais próxima da verdade, é compreensivel porque poucos de seus contemporâneos compartilharam de sua 
idéia. Os conceitos estatísticos necessários para relacionar a energia micro-mecânica com a energia macroscópica da calorimetria só foram introduzidos apenas um século depois por Maxwell, Boltzmann e Gibbs. A hipótese de Rumford não produziu resultados fenomenológicos concretos.

Embora a teoria do calórico tenha permanecido em uso durante mais de 50 anos depois do trabalho de Rumford ela, de certa forma, dificultou a solução do problema entre a conservação e a criação (ou conversão) do calórico, que intrigou grandes cientistas do século XIX. Como já mencionamos, e ainda vamos abordar posteriormente, este problema foi concretamente resolvido por meio dos trabalhos de Mayer, Joule e Helmholtz nos anos de 1840”.

Paralelamente à discussão da natureza do calor, surge também o estudo da conversão do calor em trabalho mecânico. Entra nesta conjuntura a máquina a vapor que, com o aperfeiçoamento devido a Watt nos anos de 1760, realmente tinha como objetivo principal a transformação de calor em trabalho mecânico. No entanto, isso é apenas o final da história, pois os caminhos que levaram à máquina de Watt tiveram seus inícios em outros motivos. Vejamos uma síntese desta história.

Entre os séculos XII e XVI, a lenha, era inicialmente usada para aquecer as casas durante o inverno, passou a ser utilizada também nas indústrias que começavam a se instalar. A utilização indiscriminada da lenha provocou uma devastação total das florestas, principalmente na Inglaterra. No século XVII, já não havia mais lenha suficiente. Os ingleses recorreram então ao carvão de pedra. Começou aí um importante capítulo da história da humanidade e, particularmente, da Física.

As minas de carvão na época eram superficiais, mas com o esgotamento dessas jazidas, começaram a abrir buracos e galerias cada vez mais profundas. Devido aos lençóis subterrâneos, essas minas freqüentemente ficavam inundadas de água e era necessário bombear essa água para fora para extrair o carvão. A máquina a vapor foi inventada inicialmente para este fim específico, qual seja, bombear a água para esvaziar as minas de carvão. Posteriormente, como já assinalamos, ela foi modificada e aperfeiçoada para gerar trabalho mecânico e girar rodas das máquinas nas indústrias e dos meios de transporte.

Até o final do século XVIII, todo desenvolvimento da máquina a vapor foi basicamente tecnológico e prático, faltando-lhe uma abordagem teórica fundamental. No inicio do século XIX entra em cena a figura de Sadi Carnot, cujo objetivo inicial de seus trabalhos era investigar teoricamente as possibilidades de se obter um melhor rendimento de uma máquina térmica e encontrar um limite para tal. Ben-Dov (1995) faz um hábil relato das idéias de Carnot que aqui trasladamos:

"Hoje sabemos que este limite existe. O princípio de conservação da energia indica claramente que nenhum motor pode fornecer um trabalho mecânico cujo valor energético seja superior ao do combustivel queimado. Esse princípio não existia na época de Carnot. Mas, sem conhecer sequer o conceito geral de energia, Carnot determinou um limite teórico do rendimento muito mais estrito que aquele fornecido pela conservação da energia, e o princípio que ele enunciou conserva sua validade mesmo no quadro das teorias mais modernas.

Para chegar a esse princípio, Carnot observou que, de um ponto de vista teórico, um motor térmico é semelhante a um bloco de 'matéria ativa' que se dilata quando a aquecemos $e$ se contrai quando a resfriamos. Imaginemos agora dois corpos de grandes dimensões e de temperaturas diferentes, com os quais a matéria ativa é alternadamente posta em contato. Esses dois corpos, chamados "fonte quente" e "fonte fria”, são supostamente bastante grandes para 
que o funcionamento do motor não exerça influência apreciável sobre suas respectivas temperaturas. Uma vez que a matéria ativa se dilata ao contato da fonte quente e se contrai ao contato da fonte fria, podemos utilizar seus movimentos para deslocar pesos fixados em suas extremidades, isto é, para efetuar um trabalho mecânico. No exemplo da máquina a vapor, a matéria ativa é a água que é alternadamente vaporizada e depois condensada, a fonte quente é a chama da combustão do carvão, e a fonte fria é a água que resfria o condensador externo. Encontramos essas mesmas noções no caso de um motor de automóvel: a matéria ativa é a mistura de ar e de vapor de gasolina produzida pelo carburador, a fonte quente é a explosão da mistura na câmara de combustão, e a fonte fria é o ar ambiente, para a qual são evacuados os gases de escapamento.

Nos dois casos, a matéria ativa recebe calor ao contato da fonte quente e emite calor ao contato da fonte fria. A atividade do motor é, portanto, acompanhada por uma transferência de calor da fonte quente para a fonte fria. Considerando o calor como uma substância, em conformidade com a teoria do calórico, Carnot comparou o fluxo de calor através do motor com uma queda d'água utilizada para fazer girar uma roda de pás e produzir um trabalho: o calórico 'cai' da fonte quente para a fonte fria e essa queda é aproveitada para fazer o motor funcionar. Observemos que, segundo essa analogia, a quantidade de calor extraida da fonte quente é igual àquela transmitida à fonte fria — assim como a quantidade de água que cai na montante da roda de pás é igual à que escoa na jusante. Em outras palavras, o calórico se conserva durante esse processo. Veremos que foi essencialmente sobre este ponto que se fez necessário corrigir as idéias de Carnot para adaptá-las às teorias novas que suplantaram a do calórico.

A analogia entre um fluxo de calor e uma queda d'água inspirou a Carnot as seguintes considerações: se pusermos diretamente em contato uma fonte quente e uma fonte fria, o calor passará espontaneamente da primeira para a segunda sem produzir trabalho. Podese igualmente transmitir calor entre essas mesmas fontes por intermédio de um motor, de uma matéria ativa que extraia calor da fonte quente para cedê-lo à fonte fria, efetuando ao mesmo tempo um trabalho. Nos dois casos, há transferência de calor da fonte quente para a fonte fria, mas no primeiro essa transferência se efetua sem produção de trabalho, o que, do ponto de vista que nos interessa, é puro desperdício assim como se pode deixar a água cair livremente ou, ao contrário, aproveitá-la para produzir um trabalho.

Assim, concluiu Carnot, cada vez que o calor passa espontaneamente de um corpo para outro, isto é, cada vez que dois corpos de temperaturas diferentes são postos em contato, há perda de rendimento. $O$ rendimento de um motor térmico será, portanto, tanto mais elevado quanto mais se consiga evitar os contatos diretos entre corpos de temperaturas diferentes. A melhoria introduzida por Watt na máquina de Newcomen fundava-se exatamente sobre esse principio: a adjunção do condensador externo permite evitar o contato entre o vapor quente e as paredes frias do cilindro.

Procurando então conceber um motor térmico que possuísse um rendimento máximo, um motor que não utilizasse nenhum contato direto entre corpos de temperaturas diferentes, Carnot imaginou aquecer e depois resfriar a matéria ativa, por compressão e dilatação, antes de pô-la em contato com a fonte quente e a fonte fria, respectivamente, de tal modo que os contatos se efetuassem entre corpos de temperaturas iguais. Tal motor representa, contudo, um limite ideal inatingível na prática. De fato, resulta das equações de Fourier que nenhum fluxo de calor pode escoar entre dois corpos de temperaturas iguais. Podemos, no 
entanto, obter uma aproximação da situação ideal controlando a compressão e a dilatação da matéria ativa de modo a produzir apenas diferenças muito pequenas de temperatura. Contudo, as transferências de calor permanecem demasiado lentas para que esse motor possa ter uma utilidade concreta, de modo que tal dispositivo só apresenta um interesse de estudo em laboratório.

Suponhamos, no entanto, que dispomos de um motor ideal de Carnot. Como tal motor não envolve nenhuma transferência espontânea de calor entre corpos de temperaturas diferentes, ou seja, nenhum processo irreversivel pode inverter o sentido de seu funcionamento, isto é, inverter a ordem dos processos que nele se desenrolam. Esse motor de Carnot invertido extrai calor de uma fonte fria, recebe um trabalho mecânico e depois cede calor a uma fonte quente. Um dispositivo semelhante que transfere calor de uma fonte fria para uma fonte quente absorvendo um trabalho, é chamado refrigerador. Entre os exemplos de motor invertido, citemos o refrigerador doméstico - no qual a fonte fria é o interior do refrigerador, a fonte quente é o ar ambiente $e$ o trabalho fornecido provém de um compressor alimentado eletricamente - ou ainda um condicionador de ar - que retira calor da peça que se quer refrescar e o lança para o exterior, o trabalho sendo também neste caso fornecido por um compressor. Lamentavelmente, a matéria ativa utilizada atualmente nos refrigeradores $e$ condicionadores de ar domésticos é um gás chamadofréon-um "CFC" (clorofluorcarbono) - que provoca danos consideráveis na camada de ozônio que nos protege da irradiação solar mas isso é uma outra história.

Tal como o motor de Carnot em relação aos motores reais, o refrigerador de Carnot difere dos refrigeradores reais: trata-se de um dispositivo ideal, irrealizável concretamente. De fato, o refrigerador de Carnot é reversivel em motor, ao passo que um refrigerador doméstico em que deixássemos o calor escoar em sentido inverso, do exterior para o interior, jamais se tornaria um motor capaz de fornecer um trabalho ou energia elétrica.

Suponhamos agora que, ao contrário do que dissemos, existe um motor térmico de rendimento superior ao do motor de Carnot. Podemos então, em princípio, imaginar o seguinte processo: dadas uma fonte quente e uma fonte fria, fazemos funcionar entre elas um refrigerador de Carnot, que leva certa quantidade de calórico da fonte fria para a fonte quente, absorvendo certa quantidade de trabalho. Como o refrigerador de Carnot nada mais é que um motor de Carnot invertido, essa quantidade de trabalho - que vamos chamar $\mathrm{W}$ - é idêntica ao trabalho que seria fornecido se deixássemos o calórico retornar à fonte fria por intermédio de um motor de Carnot. Mas como, por hipótese, possuímos um motor de rendimento superior ao do motor de Carnot, o trabalho que extrairíamos desse retorno de calórico - chamemo-lo $\mathrm{W}^{\prime}$ - seria superior a W. Poderíamos, portanto, efetuar esse retorno de calórico com a ajuda de nosso motor hipotético, utilizar uma fração de $\mathrm{W}$ para fazer funcionar o refrigerador de Carnot e utilizar como quiséssemos a diferença $\mathrm{W}^{\prime}-\mathrm{W}$. O calórico efetuaria assim idas e vindas entre a fonte fria e a fonte quente, permitindo-nos extrair, quando de sua passagem, um beneficio líquido de trabalho. Em outras palavras, teríamos criado trabalho a partir de nada e construido aquilo que tantas pessoas se empenharam em inventar: um 'perpetuam mobile', uma máquina de movimento perpétuo, que funcionaria eternamente sem provisão de energia.

Carnot conhecia tão bem como nós a impossibilidade do moto-perpétuo. Assim, afirmou a inexistência de um motor de rendimento superior ao de seu motor ideal, enunciando o seguinte princípio: existe um limite superior de rendimento que nenhum motor térmico pode superar. Esse limite é dado pelo motor ideal de 
Carnot, isto é, por um motor em que todos os processos são reversíveis. Em outras palavras, o rendimento de um motor reversível constitui o limite de rendimento para todo motor."

Nós poderíamos perguntar em que base Carnot se apoiou para descartar a possibilidade do que nós hoje chamamos "máquina de movimento perpétuo de primeira espécie". A resposta a isto não foi possível até 1847, quando Helmholtz avançou a hipótese sobre a conservação de energia. Com algumas exceções, parecia haver um consenso geral entre os cientistas da época, de que os poderes básicos de natureza não eram criáveis e nem indestrutíveis. Assim, por um período de muitos anos, nós percebemos a aceitação gradual do que hoje nos referimos como um postulado básico.

A máquina de Carnot reconciliou os fenômenos da conversão e da conservação - pelo menos no limite reversível. Mas, como isso é consistente com a conservação no processo de mistura altamente irreversível da calorimetria ou com a conversão no processo igualmente irreversível da geração de calor por meio da fricção? Carnot estava ciente destas dificuldades e clamou por mais experiências e, também, por uma nova avaliação dos fundamentos da teoria.

O período de pré-clássico encerrou-se com o trabalho quantitativo de Joule que estabeleceu a equivalência da energia mecânica, elétrica e química com o calor. Podemos ver que, naquele momento, ainda havia vários conceitos a serem esclarecidos. O calórico teve que ser dividido em quantidade de calor, energia e entropia. Tinha que ser mostrado que: o calor e o trabalho eram formas de transferência de energia, a inter conversibilidade entre eles é assimétrica, a energia que é conservada no calorímetro deve ser também, no Ciclo de Carnot e nos processos de atrito e, a entropia é conservada apenas no limite dos processos reversíveis.
Estes desenvolvimentos aconteceram numa sucessão relativamente rápida que começou em torno de 1850 com Clausius e prosseguiram com as contribuições importantes de Kelvin, Maxwell, Boltzmann, terminando com os brilhantes Gibbs e Planck no final do século. Nos próximos quatro itens vamos expor em pormenores alguns desses desenvolvimentos. No entanto, antes disso, com o intuito meramente didático, apresentamos uma breve cronologia das principais idéias e fatos ocorridos ao longo do desenvolvimento da aproximação histórica da Termodinâmica (PÁDUA; PÁDUA; SILVA, 2008):

100 (ad) - Héron - Inventou o eolípila, um aparelho para medir a força do vapor. Este pode ser considerado como o precursor da turbina a vapor.

1592 - Galileu construiu um termoscópio rudimentar a ar.

1620 - Bacon propôs as primeiras tentativas de diferenciar calor e temperatura. "Especulou" também, que o calor não era um fluido indestrutível (o qual posteriormente ficou conhecido como calórico) que podia entrar ou sair de um corpo, mas que era alguma forma de movimento de partículas.

1665 - Hooke escreveu "o calor é uma propriedade de um corpo proveniente do movimento ou agitação de suas partes; e, portanto, sempre que o corpo for tocado necessariamente deve receber alguma parte deste movimento e, a partir dai suas partes seriam agitadas". Esta idéia é semelhante à que mais tarde se tornou a base da Teoria Cinética dos Gases.

1687 - Papin, a partir do princípio descoberto em 1681, projetou a primeira máquina a vapor. Ele sugeriu um dispositivo com um cilindro e um pistão.

1701 - Newton sugeriu uma escala termométrica com dois pontos de referência. No primeiro associou o zero para indicar o ponto de congelamento da água e, no segundo, escolheu o número 12 para representar a temperatura do corpo humano. 
1704 - Newton fez a seguinte observação sobre o calor: "O calor consiste num minúsculo movimento de vibração das partículas dos corpos".

1712 - Newcomen reconstruiu sua máquina a vapor de uma forma mais aperfeiçoada. Foi o primeiro a utilizar um sistema com um pistão e um êmbolo.

1724 - Fahrenheit construiu um termômetro a mercúrio, tomando-se como pontos fixos, o ponto de ebulição da água $\left(212^{\circ} \mathrm{F}\right)$ e ponto de fusão do gelo $\left(32^{\circ} \mathrm{F}\right)$. Dividiu o intervalo em 180 partes iguais.

1738-Bernoulli publicou o livro "Hydrodynamica", um tratado acerca de fluidos que deu origem à Teoria Cinética dos Gases.

1742 - Celsius construiu uma escala termométrica que se tornou bastante popular. Originalmente foi chamada de escala centígrada. Tomou como pontos fixos o ponto de ebulição da água $\left(100^{\circ} \mathrm{C}\right)$ e ponto de fusão do gelo $\left(0^{\circ} \mathrm{C}\right)$. Dividiu o intervalo em 100 partes iguais.

1747 - Richmann observou que quantidades distintas de uma mesma substância, num mesmo estado de agregação, necessitam quantidades de calor diferentes para a mesma elevação de temperatura. Isto era um indicio de que o calor era diferente da temperatura.

1760 - Black propôs a teoria do calórico.

1765 - Watt desenvolveu finalmente uma máquina a vapor mais eficiente e econômica. Adaptou na máquina de Newcomen um condensador externo, assim, caldeira era o reservatório quente, e, o condensador, o reservatório frio.

1770 - Black mostrou experimentalmente que a temperatura é uma característica do corpo.

1783 - Lavoisier e Laplace determinaram experimentalmente o calor específico para vários materiais e construíram o calorímetro de gelo.

1798 - Conde de Rumford depois de vários experimentos quantitativos sugeriu: "o calor desenvolvido em uma operação com um canhão deveria provir da energia mecânica gasta neste processo".

1799 - Davy concluiu, a partir de suas experiências, que o calor era cinético por natureza, ou seja, uma forma de movimento.

1803 - Dalton formulou sua teoria atômica.

1819-Dulonge Petitverificaram experimentalmente que o calor específico dos sólidos multiplicado pelo peso atômico tem um valor constante em relação à variação da temperatura.

1824 - Carnot publicou o seu famoso trabalho "Reflexões sobre a Potência Motriz do Fogo". A primeira tentativa de uma abordagem racional da relação entre calor e trabalho foi feita neste trabalho.

1834 - Clapeyron publicou o trabalho "Memórias sobre a Potência Motriz do Calor". Deu um tratamento analítico e uma representação gráfica aos resultados de Carnot.

1842 a 1843 - Mayer propôs que: "o calor era uma manifestação da energia, assim como o trabalho e, que existe uma relação entre eles".

1845 - Joule propôs um aparato, por meio do qual determinou experimentalmente o valor do equivalente mecânico do calor. Neste trabalho, ele conclui que $1 \mathrm{cal}=4,154 \mathrm{~J}$. O valor atual é: $1 \mathrm{cal}=$ $4,186 \mathrm{~J}$

1847 - Helmholtz estabeleceu definitivamente a idéia do calor como uma forma de energia, sob o formato de um Princípio da Conservação da Energia, que atualmente denominamos de Primeira Lei da Termodinâmica.

1846 a 1848 - Lord Kelvin, ao trabalhar no laboratório do químico francês Henri Victor Régnault (1810 - 1878) e estudar as obras de Carnot e de Clapeyron, propôs a adoção de uma escala absoluta de temperatura.

1850 - Clausius modificou o tratamento desenvolvido por Carnot, com o objetivo de descrever a irreversibilidade dos processos naturais. 
1856 - Kelvin estabeleceu definitivamente a escala do gás ideal, chamada então de escala absoluta de Kelvin ou escala termodinâmica de temperatura.

1865 - Clausius propôs uma formalização teórica para um ciclo reversível qualquer, construindo-o a partir de uma sucessão de ciclos de Carnot. Para isso, introduziu uma nova função de estado, que foi por ele denominada de entropia. Este termo tem origem na palavra grega 'entropé', que quer dizer mudança, volta ou transformação.

\section{Temperatura e natureza do calor}

Os sistemas físicos descritos pela Termodinâmica são sistemas grandes, com um número de constituintes tipicamente da ordem do número de Avogadro $\left(\sim 10^{23}\right)$. A descrição macroscópica de um sistema termodinâmico simples envolve apenas um número muito pequeno de parâmetros ou devariáveis. Variáveis como a temperatura e a pressão, que não dependem do tamanho do sistema, são chamadas de variáveis intensivas e variáveis como o volume e a energia interna, que de alguma forma estão ligadas ao tamanho do sistema, são denominadas variáveis extensivas. Todas estas grandezas são consideradas como variáveis ou funções de estado do sistema termodinâmico. Aos pares, elas definem o estado de um sistema termodinâmico fechado. Por exemplo, se fixamos a temperatura, podemos estudar o comportamento da pressão do sistema em função do volume.

A idéia de temperatura foi inicialmente, e ainda de alguma forma continua, associada à nossa sensação de quente e frio. Um "corpo quente" tem uma alta temperatura e um "corpo frio" uma temperatura baixa. Numa situação intermediária, um "corpo morno" tem uma temperatura média. Dessa forma, a temperatura é uma grandeza que define o estado térmico do corpo. No entanto, estas são apenas observações muito subjetivas, que não servem para a Física.
Entretanto, com o desenvolvimento dos termômetros, a temperatura foi o primeiro conceito termodinâmico a atingir um status operacional, ou seja, a ser medido objetivamente.

'Estabelecida' a idéia de temperatura, surge uma outra questão: Quando colocamos um corpo quente em contato com um corpo frio, o quente esfria e o frio esquenta. $\mathrm{Na}$ linguagem da temperatura, o quente ficou com uma temperatura menor do que estava e o frio aumentou sua temperatura. Depois de muito tempo, eles ficam no mesmo estado térmico, ou seja, numa mesma temperatura. Hoje dizemos que eles atingiram o equilíbrio térmico. Com base nisto, faz-se as seguintes perguntas: O que passa de um corpo para outro? Será a própria temperatura? Será 'algo' diferente da temperatura? Se não for a temperatura, o que é ou quem é este 'algo'? Este 'algo' não é a temperatura, mas o calor. Antes de falarmos acerca do calor e sua natureza, precisamos primeiro esclarecer alguns pontos relativos à precedência dos conceitos temperatura e calor.

Na verdade, cronologicamente, os conceitos calor e temperatura foram aqui apresentados em ordem contrária, uma vez que idéia de calor antecede a de temperatura.

Aristóteles, que formulou suas teorias em termos de qualidades sensíveis, via no calor e no frio, duas 'qualidades' elementares, opostas e simétricas. Do calor em particular, pensava-se que era uma propriedade que um corpo tem de ser quente ao toque. Estas definições, aqui apenas filosóficas, fundaramse também nas observações em certos seres vivos, tais como a febre e o calafrio. Por incrível que pareça, estas noções, fora do ambiente científico, perduram até hoje e ainda são corroboradas nos melhores dicionários. Vejamos o que diz um deles sobre o calor. Sensação que se experimenta, em ambiente aquecido (pelo Sol ou artificialmente), ou junto de objeto quente elou que se aquece: Ao entrar na sala sentiu calor; $O$ calor do agasalho provocava-lhe abundante transpiração. Qualidade 
ou estado de quente; quentura: o calor do Sol; o calor da febre.

Coloquemos uma panela com água sobre o fogo. A água vai aquecendo progressivamente e, após um certo tempo, se a deixarmos ainda no fogo, ela entra em ebulição e se transforma em vapor. Parece que o fogo transmite 'algo' à água que a faz aquecer e depois transformar em vapor. Este 'algo' cuja natureza exata, mesmo hoje, ainda não conhecemos foi denominada de 'calor'. A seguir, vamos relatar brevemente alguns pontos de sua evolução histórica. Por enquanto, exploremos mais um pouco esta linha de raciocínio.

No caso do aquecimento da água, inspirando- nos ainda em Aristóteles, dizemos que o calor passou do fogo para a água e não que a 'frieza' passou da água para o fogo. Neste raciocínio, podemos perceber que há uma assimetria essencial entre o quente e o frio.

Voltemos agora à questão da temperatura. Se desejarmos medir o grau de 'quentura', vamos lançar mão de uma grandeza física que denominaremos de temperatura. No exemplo da água sobre o fogo, podemos observar e desenvolver o seguinte raciocínio corroborado empiricamente. Quando levamos a panela com água ao fogo, este vai transmitindo 'calor' à água e ela vai ser tornando cada vez mais quente. Se pensarmos em termos da temperatura, podemos concluir que, em cada instante sua temperatura vai aumentando.

Neste ponto, ainda não distinguimos temperatura de calor. Sinteticamente, podemos dizer: muito calor parece associa-se a alta temperatura. A esta altura, pensamos da seguinte forma: quando um corpo recebe calor sua temperatura aumenta e, quando um corpo se esfria, não é que ele recebe frieza, pois isto não pode ocorrer. Ele na verdade perde calor.

No exemplo da água, quando ao ser aquecida pelo fogo, chega no ponto de ebulição, durante este processo de aquecimento seu grau de 'quentura', ou seja, sua temperatura, se estabiliza, mas o fogo tem que continuar fornecendo calor, para que a vaporização continue. Eis aqui um primeiro ponto que diferencia temperatura de calor. A temperatura parece ser uma característica da água em cada instante, enquanto o calor, não. A temperatura parece ser uma função de estado da água. Ela caracteriza o estado térmico da água em cada instante do processo de aquecimento.

A partir desses dois últimos parágrafos, podemos concluir que: a temperatura parece caracterizar o estado de um corpo em um dado instante, enquanto que o calor é uma entidade física que se transmite de um corpo para outro. Quando um corpo recebe calor se esquenta e aumenta sua temperatura, mas, quando, se esfria, e diminui sua temperatura. Ocorre também que o corpo, ao receber calor, não esquenta, e não varia sua temperatura, mas muda de seu estado de agregação ou de fase.

Torna-se bastante difícil de responder o que é o fenômeno denominado calor. Uma idéia inicial e até hoje mais imediata ao homem comum, poderia ser pensada da seguinte forma: quando aquecemos um corpo, sua temperatura aumenta. Parece que isto ocorre porque no aquecimento transferimos 'algo' a este corpo. Se isso for correto, como explicaríamos os seguintes casos: a) um projétil, quando disparado, aquece o cano da arma, b) quando um peso cai e gira uma hélice dentro de um recipiente hermeticamente fechado com água, aquece esta água e c) freqüentes marteladas num pedaço de ferro, aquecem este material (BEN-DOV, 1995).

Como já citamos, no século XVII havia duas hipóteses acerca da natureza do calor. A primeira, denominada teoria do calórico, dizia que o calor era uma substância denominada calórico. Galileu foi um dos adeptos desta hipótese (1613). A segunda, conhecida como teoria mecânica do calor, foi proposta inicialmente por Bacon em 1620, corroborada por Hooke em 1665 e por Newton em 1704 e, reconhecida por Bernoulli em 1738. No entanto, ela só foi realmente aceita em meados do século XIX (ENCYCLOPAEDIA BRITANNICA, 
1979; NUSSENZVEIG, 1981; PÁDUA; PÁDUA; SILVA, 2008).

$\mathrm{Na}$ teoria do calórico, o calor era considerado com um fluido sutil que preenchia o interior dos corpos. Espalhado por toda a natureza, esse fluido era propagado ou conservado pelos corpos, de acordo com suas propriedades e temperaturas. Assim sendo, a temperatura media a pressão ou a densidade do calórico contido em um corpo e uma transferência de calor entre dois corpos era interpretada como um escoamento de calórico no sentido decrescente da pressão.

Pensava-se que calórico era atraído pelos átomos das substâncias, mas era auto-repelente. Formavase uma nuvem de calórico em torno de cada átomo e estas nuvens se repeliam entre si, evitando assim que os átomos se aproximassem demasiadamente. A temperatura dependia da densidade de calórico na superfície do corpo. Para aumentar a temperatura, fornecia-se calórico ao corpo. Isso aumentava não só o calórico na superfície, mas também a repulsão entre os átomos, fazendo com que o corpo aumentasse de volume.

Pelo menos cinco pontos depunham a favor da teoria do calórico: a) ela beneficiava-se do fato de que os cálculos de escoamentos de fluidos ordenados são em geral muito mais simples que a determinação dos movimentos simultâneos de um grande número de partículas; b) a idéia do calórico foi favorecida pelos progressos ocorridos na química no século XVIII. O calórico era um elemento que participava efetivamente das reações químicas envolvendo calor. O gelo sólido derrete e se transforma em água líquida. O calórico reage com o gelo e forma água; c) O êxito da teoria de Laplace, que explicou uma disparidade considerável que aparecia entre a velocidade do som medida no ar e aquela que Newton calculou por via teórica a partir de sua mecânica, supondo, como se passou desde então, a admitir que o som é uma vibração do ar. $\mathrm{O}$ valor de Newton diferia em $20 \%$ do valor observado. Laplace se baseou no fato bem conhecido: o ar se aquece quando comprimido e se esfria ao se distender; d) em 1822, Fourier formulou as equações de escoamento dos fluxos de calor de forma semelhante ao escoamento dos líquidos em geral e, e) o mais interessante triunfo da teoria do calórico, porém, é devido a Carnot. Carnot se interessou pelo rendimento das máquinas térmicas, que produziam trabalho mecânico a partir do calor. Duas observações acerca da obra de 1824: i) ela não despertou um interesse momentâneo - foi reconhecida apenas décadas depois, ii) embora suas idéias tenham sido formuladas no âmbito da teoria do calórico, as conclusões de Carnot tiveram um alcance muito mais geral.

A principal dificuldade enfrentada pela teoria do calórico, porém, estava na "lei da conservação do calórico", pois a quantidade de calórico que podia ser 'espremida para fora' de um corpo por atrito era ilimitada como havia verificado Rumford (BENDOV, 1995; ENCYCLOPAEDIA BRITANNICA, 1979; MODELL; REID, 1974; NUSSENZVEIG, 1981; PÁDUA; PÁDUA; SILVA, 2008; SEGRÈ, 1980).

Mesmo diante dessa dificuldade, a teoria do calórico explicava quase todos os fenômenos térmicos e foi aceita durante todo o século XVIII. No entanto, ela foi abandonada, em meados do século XIX, porque ficou mais claro que o calor era uma forma de energia que passava de um corpo a outro e deveria estar associado às energias de movimento de todos os átomos constituintes do corpo.

Na teoria mecânica, o calor era uma 'vibração' dos átomos que compunham a matéria. Assim, a temperatura representava a intensidade dessas vibrações e uma transferência de calor era uma propagação das mesmas. Quando dois corpos de temperaturas diferentes eram postos em contato, os átomos do corpo mais quente comunicavam parte de suas vibrações aos do corpo mais frio por meio de colisões e, esse processo continuava até que os átomos dos dois corpos vibrassem com intensidades iguais. 
A idéia do calor como resultado do movimento molecular foi levantada por Rumford, Davy, Lavoisier e Laplace. Estes não encontraram, todavia, métodos suficientemente eficientes para explorá-la com maior profundidade.

Entendendo o calor como uma forma de energia, uma energia que se transfere dos modos microscópicos ocultos de movimentos dos constituintes do sistema, podemos fazer a seguinte síntese das noções acerca de temperatura (ENCYCLOPAEDIA BRITANNICA, 1979):

Se o corpo é sólido, o movimento de seus átomos é de vibração em torno de uma posição de equilibrio: quanto maior a temperatura, mais intensas são estas vibrações e,

Se é um gás ou um líquido, seus átomos (ou moléculas) se deslocam com velocidades tanto maiores, quanto maior for a temperatura.

\section{O Ciclo de Carnot}

Carnot demonstrou que, para o funcionamento de uma máquina térmica, deve existir uma fonte quente e uma fonte fria e que, quando uma quantidade de calor é transportada da primeira para a segunda, por meio de uma substância qualquer, um trabalho mecânico é realizado. Ele fez uma analogia da máquina térmica ou motor térmico ou ainda 'máquina a fogo', como ficou popularmente conhecida, com um moinho movido por uma roda d'água. Da mesma forma que precisa de uma queda d'água para acionar um motor hidráulico, também é necessária uma 'queda' de temperatura para se impulsionar um motor térmico. A analogia mecânica que guiou a pesquisa de Carnot, deixou imprecisa a natureza do calor, pois ele sugeriu uma interpretação com base na teoria do fluido calórico. Todavia, foi a partir dessas considerações que Carnot postulou o seguinteprincípiofundamental(ENCYCLOPAEDIA BRITANNICA, 1979; PÁDUA; PÁDUA; SILVA, 2008): "Em uma máquina térmica funcionando em condições ideais, a uma certa quantidade de calor fornecido à caldeira corresponde um trabalho recolhido, independentemente dos agentes postos em ação para realizá-lo. Esse trabalho é fixado unicamente pelas quantidades de calor trocadas entre o motor térmico e o ambiente".

Deixando de lado o problema técnico da construção de máquinas a vapor, Carnot procurou uma regra que permitisse relacionar entre si a energia mecânica por elas produzida e o calor fornecido. Intuiu, dessa forma, o primeiro princípio da Termodinâmica, que é apenas uma reafirmação do princípio da conservação de energia.

Carnot, depois de realizar uma análise cuidadosa do funcionamento do motor térmico, idealizou uma máquina que, trabalhando com um gás aquecido e resfriado (podia ser até o vapor d'água), servia para medir a quantidade de energia mecânica produzida e permitia também, calcular a porcentagem de energia térmica transformada em mecânica. O funcionamento dessa máquina é constituído por quatro fases ou processos, formando um ciclo fechado que hoje é chamado de Ciclo de Carnot. Um sistema submetido a este ciclo, passa pelas seguintes transformações: a partir de um estado inicial, o sistema expande-se isotermicamente (absorvendo calor do ambiente) até atingir um segundo estado; a partir deste, a expansão é adiabática e, conseqüentemente, a temperatura diminui; daí em diante, o volume do sistema começa a reduzir-se isotermicamente até alcançar um último estado; uma compressão adiabática conduz o sistema ao seu ponto de partida, fechando-se, assim, o ciclo.

Uma das características do Ciclo de Carnot é o fato de que as transformações que ocorrem ao longo do mesmo são totalmente reversíveis, isto é, podem ser realizadas em sentido inverso, percorrendo as mesmas etapas intermediárias. Esse ciclo pode ser aplicado a qualquer máquina térmica.

Carnot mostrou que qualquer máquina térmica que opera segundo o seu ciclo tem um rendimento máximo (ideal) e que este independe da substância 
de trabalho. O rendimento é função apenas das duas temperaturas entre as quais a máquina opera.

Para mostrarmos analiticamente este teorema de Carnot, consideremos um gás ideal qualquer como substância de trabalho (PÁDUA; PÁDUA, 2006; SOMMERFELD, 1964; SONNTAG; BORGNAKKE; VAN WYLEN, 1998; TIPLER, 2000). A Equação de Estado para um gás ideal, como sabemos, é dada pela seguinte expressão:

$$
\mathrm{PV}=\mathrm{nRT} \text {. }
$$

Num processo isotérmico, considerando que a energia interna de um gás ideal, depende da temperatura por meio da expressão $U=(\kappa / 2) n R T$ ( $\kappa=$ número de graus de liberdade da molécula do gás), temos que: $\mathrm{T}=$ cte $\Rightarrow \Delta \mathrm{U}=0 \Rightarrow|\mathrm{Q}|=|\mathrm{W}|$. Usamos aqui a expressão $\Delta \mathrm{U}=\mathrm{Q}-\mathrm{W}$.

Com base nesta condição e utilizando-se a expressão (1), podemos escrever:

$\left|\mathrm{W}_{\mathrm{ab}}\right|=\left|\mathrm{Q}_{\mathrm{ab}}\right|=\int_{\mathrm{V}_{\mathrm{a}}}^{\mathrm{V}_{\mathrm{b}}} \mathrm{PdV}=\mathrm{nRT} \int_{\mathrm{V}_{\mathrm{a}}}^{\mathrm{V}_{\mathrm{b}}} \frac{1}{\mathrm{~V}} \mathrm{dV}=\mathrm{nRT} \ln \left(\frac{\mathrm{V}_{\mathrm{b}}}{\mathrm{V}_{\mathrm{a}}}\right) . \quad\left(\mathrm{T}_{\mathrm{a}}=\mathrm{T}_{\mathrm{b}}=\mathrm{T}\right)$.

A figura 1 ilustra um processo isotérmico no diagrama $\mathrm{P}-\mathrm{V}$ entre os estados de equilíbrio a e b.

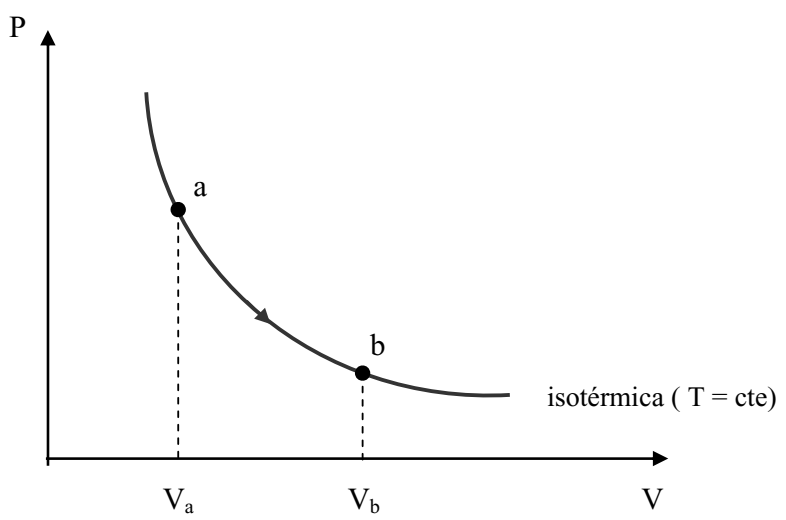

Figura 1. Processo isotérmico no diagrama PV.
Num processo adiabático para um gás ideal, temos que:

$$
\mathrm{PV} \gamma=\text { cte. }
$$

Assim, pelo gráfico da figura 2, que ilustra um processo adiabático entre aos estados de equilíbrio b e c, podemos escrever:

$$
\mathrm{P}_{\mathrm{b}} \mathrm{V}_{\mathrm{b}}^{\gamma}=\mathrm{P}_{\mathrm{c}} \mathrm{V}_{\mathrm{c}}^{\gamma}
$$

Num processo adiabático se substituirmos (1) em (3), encontramos:

$$
\mathrm{TV}^{\gamma-1}=\text { cte. }
$$

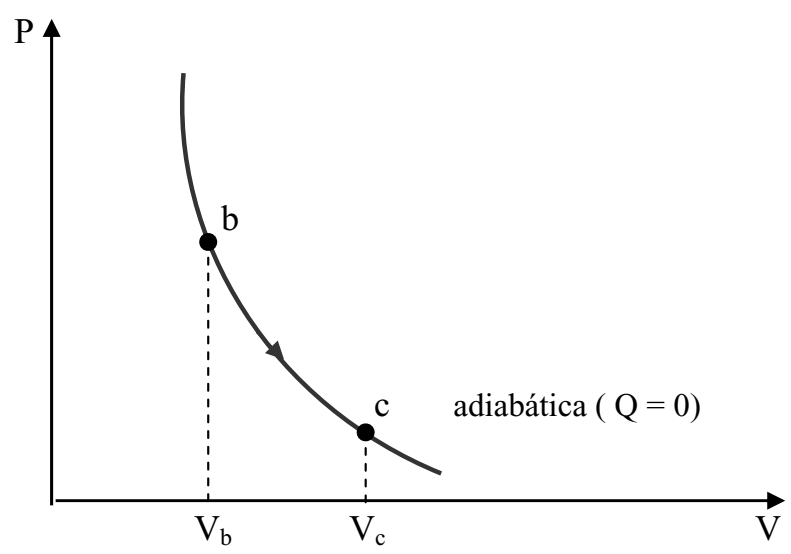

Figura 2. Processo adiabático no diagrama PV.

Nas figuras 3 e 4, ilustramos o Ciclo de Carnot no plano $\mathrm{P}-\mathrm{V}$. Na figura 3, mostramos uma máquina térmica de Carnot. Nesta, o ciclo é percorrido no sentido horário e o trabalho feito por ela é positivo. $\mathrm{Na}$ figura 4, mostramos um refrigerador de Carnot. Nesta, o ciclo é percorrido no sentido anti-horário e o trabalho feito por ela é negativo. [Em ambas figuras, a letra $\mathrm{Q}$ indica a fonte quente, $\mathrm{F}$ a fonte fria e $\mathrm{W}$ o trabalho mecânico realizado pela máquina] 


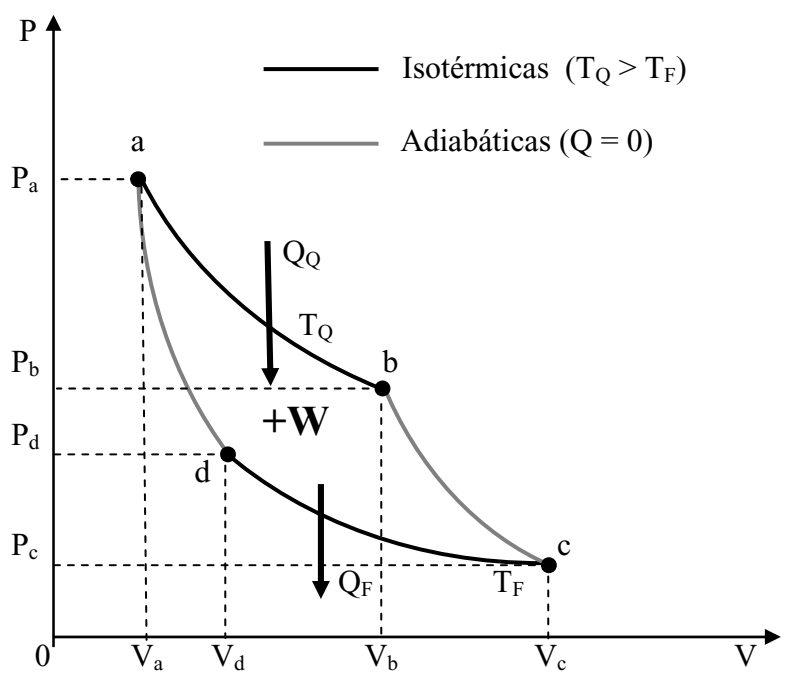

Figura 3. Representação do ciclo percorrido por uma Máquina Térmica de Carnot.

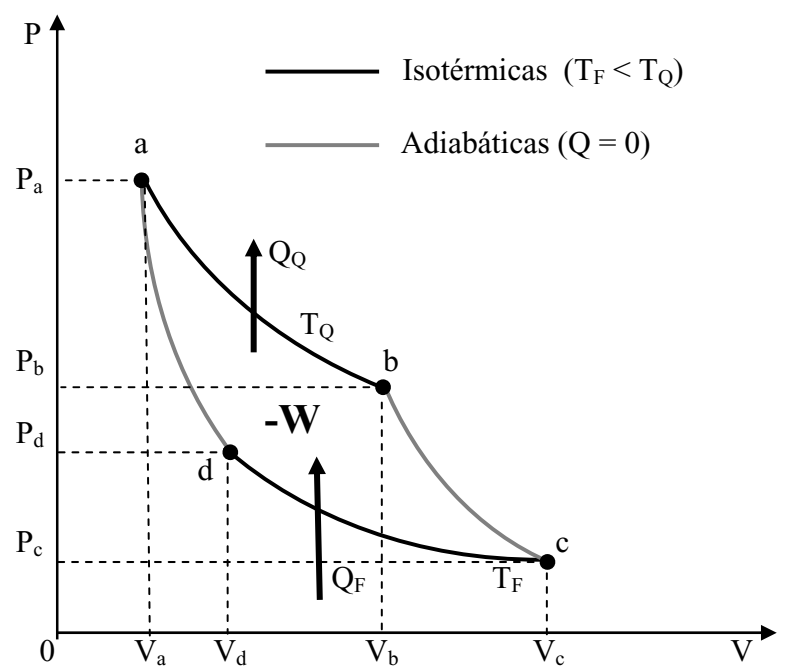

Figura 4. Representação do ciclo percorrido por um Refrigerador de Carnot.

Os resultados (2) e (5), juntamente com as figuras 3 e 4, servirão de base para desenvolvermos os cálculos a seguir. Como vamos trabalhar com módulos de $\mathrm{Q}$ e de $\mathrm{W}$, a demonstração vale para máquinas térmicas e refrigeradores ideais. Vejamos!

$$
\begin{aligned}
& \left.\begin{array}{l}
\text { Processo: } \mathrm{a} \rightarrow \mathrm{b} \\
\left|\mathrm{W}_{\mathrm{Q}}\right|=\left|\mathrm{Q}_{\mathrm{Q}}\right|=\mathrm{nRT}_{\mathrm{Q}} \ln \left(\frac{\mathrm{V}_{\mathrm{b}}}{\mathrm{V}_{\mathrm{a}}}\right) \\
\begin{array}{l}
\text { Processo: } \mathrm{c} \rightarrow \mathrm{d} \\
\mathrm{W}_{\mathrm{F}}|=| \mathrm{Q}_{\mathrm{F}} \mid=\mathrm{nRT}_{\mathrm{F}} \ln \left(\frac{\mathrm{V}_{\mathrm{c}}}{\mathrm{V}_{\mathrm{d}}}\right)
\end{array} \\
\begin{array}{l}
\text { Processo: } \mathrm{b} \rightarrow \mathrm{c} \\
\mathrm{T}_{\mathrm{Q}} \mathrm{V}_{\mathrm{b}}^{\gamma-1}=\mathrm{T}_{\mathrm{F}} \mathrm{V}_{\mathrm{c}}^{\gamma-1}
\end{array} \\
\begin{array}{l}
\text { Processo: } \mathrm{d} \rightarrow \mathrm{a} \\
\mathrm{T}_{\mathrm{Q}} \mathrm{V}_{\mathrm{a}}^{\gamma-1}=\mathrm{T}_{\mathrm{F}} \mathrm{V}_{\mathrm{d}}^{\gamma-1}
\end{array}
\end{array}\right\} \Rightarrow \frac{\left|\mathrm{Q}_{\mathrm{Q}}\right|}{\left|\mathrm{Q}_{\mathrm{F}}\right|}=\frac{\mathrm{T}_{\mathrm{Q}}}{\mathrm{T}_{\mathrm{F}}} \cdot \frac{\ln \left(\frac{\mathrm{V}_{\mathrm{b}}}{\mathrm{V}_{\mathrm{a}}}\right)}{\ln \left(\frac{\mathrm{V}_{\mathrm{c}}}{\mathrm{V}_{\mathrm{d}}}\right)} \\
& \frac{\mathrm{V}_{\mathrm{b}}^{\gamma-1}}{\mathrm{~V}_{\mathrm{a}}^{\gamma-1}}=\frac{\mathrm{V}_{\mathrm{c}}^{\gamma-1}}{\mathrm{~V}_{\mathrm{d}}^{\gamma-1}} \Rightarrow \frac{\mathrm{V}_{\mathrm{b}}}{\mathrm{V}_{\mathrm{a}}}=\frac{\mathrm{V}_{\mathrm{c}}}{\mathrm{V}_{\mathrm{d}}}
\end{aligned}
$$

Substituindo-se (7) em (6) obtemos, para uma máquina térmica ideal (ou refrigerador ideal), ou seja, de Carnot, a seguinte relação fundamental:

$$
\frac{\left|\mathrm{Q}_{\mathrm{Q}}\right|}{\left|\mathrm{Q}_{\mathrm{F}}\right|}=\frac{\mathrm{T}_{\mathrm{Q}}}{\mathrm{T}_{\mathrm{F}}} .
$$

Observações: a) Lembrar que $\mathrm{T}_{\mathrm{Q}}$ e $\mathrm{T}_{\mathrm{F}}$ são expressas em kelvin. Na verdade, foi Kelvin quem mostrou matematicamentea relação(8).b) Otrabalho de Carnot de 1824 não se primou por demonstrações feitas através de cálculos matemáticos, mas sim por análises expressas em uma linguagem precisa e cuidadosa. As demonstrações formais foram feitas por Clapeyron em 1834 e 1843 e, por Clausius em 1850. Num trabalho posterior abordaremos esta questão.

Com o resultado da equação (8), o rendimento de uma máquina térmica (e) e o coeficiente de performance de um refrigerador $(K)$, que são definidos em termos de $\mathrm{Q}_{\mathrm{Q}}$ e $\mathrm{Q}_{\mathrm{F}}$, podem ser expressos apenas em função de $T_{Q}$ e $T_{F}$. As expressões do rendimento $\underline{\mathrm{e}}$ do coeficiente de performance $\underline{\mathrm{K}}$ podem então, ser escritos de forma bastante completa e ilustrativa como segue (PÁDUA; PÁDUA, 2006; SMITH; VAN NESS; ABBOTT, 2000; SONNTAG; BORGNAKKE; VAN WYLEN, 1998; TIPLER, 2000): 
Rendimento:

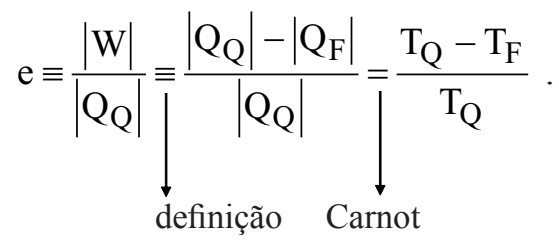

\section{Coeficiente de performance:}

$$
\mathrm{K} \equiv \frac{\left|\mathrm{Q}_{\mathrm{F}}\right|}{|\mathrm{W}|} \equiv \frac{\left|\mathrm{Q}_{\mathrm{F}}\right|}{\left|\mathrm{Q}_{\mathrm{Q}}\right|-\left|\mathrm{Q}_{\mathrm{F}}\right|}=\frac{\mathrm{T}_{\mathrm{F}}}{||_{\text {Cérinição }}^{\mathrm{T}_{\mathrm{Q}}-\mathrm{T}_{\mathrm{F}}}} .
$$

\section{Equivalente mecânico do calor}

O desenvolvimento da máquina a vapor por James Watt e as experiências de Rumford acerca do aquecimento produzido pelo atrito em rotações rápidas, levantaram a questão da correspondência entrecalore trabalhomecânico. Os efeitos observados por Rumford eram totalmente incompatíveis com as teses simplistas dos defensores do calórico.

A máquina a vapor desenvolvida na segunda metade do século XVIII foi uma demonstração prática da capacidade de produzir trabalho por intermédio do calor. No entanto, como já mencionamos, somente no século seguinte uma conexão mais precisa entre eles foi estabelecida. Mais exatamente em torno da metade do século XIX.

A idéia de que a energia se apresenta em diversas formas não surgiu espontaneamente. Até o início do século XIX, por energia entendia-se apenas energia mecânica, ou seja, cinética e potencial. A verificação de que a energia cinética pode ser transformada em calor foi quem abriu caminho para essa nova concepção.

A nosso ver, o resultado encontrado por Rumford contribuiu decisivamente para derrubar a teoria do calórico, pois mostrou que o trabalho mecânico era o verdadeiro responsável pelo aparecimento do calor na operação de perfurar os canhões. No entanto, a teoria correta como dissemos, só foi plenamente desenvolvida quase 50 anos mais tarde, graças aos trabalhos de Helmholtz, Mayer e Joule (ENCYCLOPAEDIA BRITANNICA, 1979; NUSSENZVEIG, 1981; PÁDUA; PÁDUA; SILVA, 2008; PRIGOGINE, 1999; SEGRÈ, 1980; SOMMERFELD, 1964).

Mayer, observando que o trabalho, por exemplo, através do atrito, podia ser convertido em calor, afirmou:

"Se energia cinética e potencial são equivalentes ao calor, é natural que calor seja equivalente às energias cinética e potencial", ou seja, o calor é uma forma de energia. A partir daí ele formulou um problema crucial: "Qual é a quantidade de calor que corresponde a uma dada quantidade de energia cinética ou potencial?" (Em síntese, qual o valor do equivalente mecânico do calor?)

Na época Mayer, deduziu um valor do equivalente mecânico do calor com um erro da ordem de $10 \%$.

Joule em 1845, por meio de sua famosa terceira experiência, que lhe trouxe fama e tornou-se clássica pela sua engenhosidade, mediu como já informamos, o equivalente mecânico do calor com uma excelente precisão para os padrões da época. Um fato interessante que ocorreu em 1847, quando Joule aos 29 anos, apresentou numa reunião em Oxford um de seus resultados mais confiáveis, foi que um jovem da platéia manifestou um grande interesse pelo assunto. Este jovem, com então 23 anos, era William Thomson, o futuro Lorde Kelvin. No entanto, os melhores resultados de Joule foram obtidos somente em 1868.

Em seu experimento, Joule não empregou mais que um recipiente cheio de água, um termômetro, dois corpos pesados e uma haste metálica dotada de algumas pás. Numa das extremidades da haste, 
havia uma carretilha. A haste era imersa na água, de modo que as pás pudessem girar livremente no interior do líquido. Da carretilha, que permanecia fora do recipiente, saíam dois fios em direções opostas, cada um dos quais passando por roldanas com eixos dispostos horizontalmente. $\mathrm{Na}$ ponta dos fios, amarravam-se os corpos pesados. O bulbo do termômetro, imerso na água, permitia medir a temperatura.

A experiência consistia tão somente em suspender os dois corpos pesados, por meio da carretilha e, depois liberá-la. Os corpos, atraídos pela Terra, caíam, fazendo a carretilha girar; esse movimento se transmitia à haste metálica, e dessa maneira as pás giravam rapidamente no interior da água. Como conseqüência, a temperatura da água se elevava. Este aumento da temperatura era registrado pelo termômetro. Conhecendo-se a massa e altura de queda dos corpos, Joule pôde calcular a energia fornecida ao sistema (água) na forma de energia mecânica ( $\mathrm{U}=\mathrm{W}=\mathrm{mgh}$ ) e, pela medida da variação de temperatura e pelos dados da água ( $\mathrm{n}, \mathrm{c}_{\text {água }}$ ), ele calculou a quantidade líquida de calor que the era fornecida $\left(\mathrm{Q}=\mathrm{nc}_{\text {água }} \Delta \mathrm{T}\right)$. Com estes dois dados, ele determinou o equivalente mecânico do calor ( $\mathrm{J}=\mathrm{W} / \mathrm{Q}$ ). A figura 5 a seguir, mostra uma representação do equipamento utilizado por Joule (ENCYCLOPAEDIA BRITANNICA, 1979; PÁDUA; PÁDUA; SILVA, 2008).

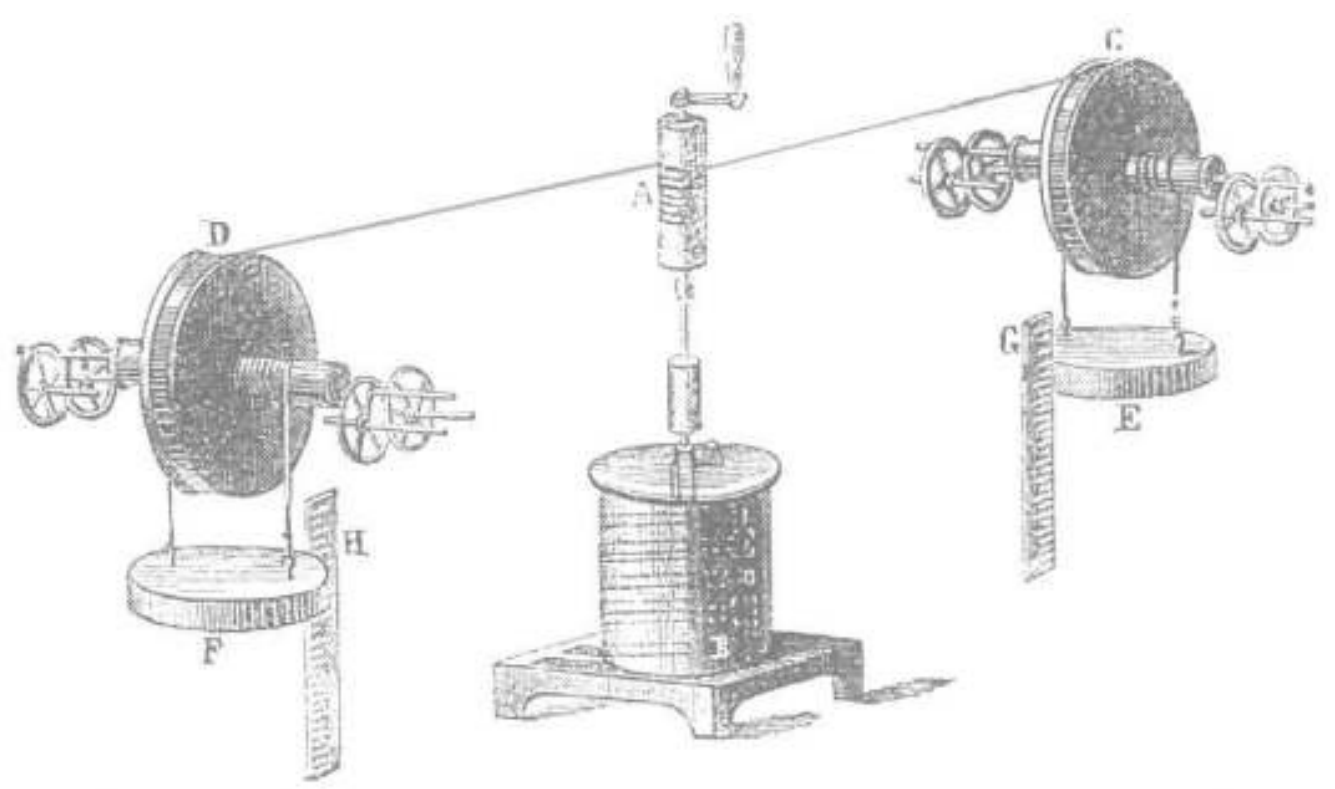

Figura 5. Ilustração do equipamento utilizado por Joule para medir o equivalente mecânico do calor (J). 


\section{As três leis empíricas básicas}

\section{Lei Zero da Termodinâmica}

O conceito de temperatura é importante para a primeira e segunda lei da Termodinâmica. No entanto, a lei baseada no equilíbrio térmico, como a conhecemos e usamos hoje, em que a temperatura é formalmente definida, só apareceu na década de 1930. Como a temperatura é a primeira grandeza fundamental na Termodinâmica, esta lei naturalmente deveria preceder as duas leis já existentes. Portanto, foi então chamada originalmente por Fowler e Guggenhein de Lei Zero da Termodinâmica. Podemos enunciá-la da seguinte forma (ENCYCLOPAEDIA BRITANNICA, 1979; KONDEPUDI; PRIGOGINE, 1999; MORSE, 1969; NUSSENZVEIG, 1981; PÁDUA; PÁDUA, 2006; SEGRÈ, 1980; SOMMERFELD, 1964; SONNTAG; BORGNAKKE; VAN WYLEN, 1998; TIPLER, 2000):

"Dois sistemas termodinâmicos, quando em equilíbrio térmico com um terceiro sistema, estão em equilibrio térmico entre si”.

Definições de termos pertinentes à lei zero:

Equilíbrio: um sistema termodinâmico está em equilíbrio no sentido macroscópico, quando suas variáveis macroscópicas de estado são constantes no tempo e uniformes através de todo o sistema.

Equilíbrio Térmico:doissistemastermodinâmicos estão em equilíbrio térmico se, quando postos em contato por meio de uma parede diatérmica, suas variáveis de estado não se alteram. Dois sistemas em equilíbrio térmico têm a mesma temperatura.

\section{Observações:}

a) Maxwell, no início da segunda metade do século XIX, observou que dois corpos com temperaturas iguais a de um terceiro tinham também a mesma temperatura.

b) De forma substancial, podemos dizer que a Lei Zero da Termodinâmica traz em si o princípio físico do Equilíbrio Térmico e, nos proporciona uma maneira empírica de definir temperatura e estabelece um processo operacional de como medi-la.

\section{Primeira Lei da Termodinâmica}

A história desta lei foi bastante longa. Ela se desdobrou basicamente ao longo de toda a primeira metade do século XIX. Para a sua formulação definitiva, vários experimentos foram realizados durante este período. Os grandes problemas enfrentados foram: a idéia da existência de uma substância denominada calórico e a relação entre o calor e o trabalho.

Os principais cientistas que contribuíram decisivamente para sua formulação foram: Carnot, Mayer, Joule, Helmholtz, Clausius e Kelvin (ENCYCLOPAEDIA BRITANNICA, 1979; KONDEPUDI; PRIGOGINE, 1999; MODELL; REID, 1974; MORSE, 1969; NUSSENZVEIG, 1981; PÁDUA; PÁDUA, 2006; PÁDUA; PÁDUA; SILVA, 2008; SOMMERFELD, 1964).

Em linhas gerais, essa lei é uma manifestação do princípio da conservação da energia. Num sistema termodinâmico isolado, estabelece-se que a energia interna permanece constante.

Hoje, sabemos que a energia interna é a energia que existe no interior do sistema e que é igual à soma da energia cinética e potencial das moléculas que compõem o sistema.

Com o intuito de enfatizar um pouco mais o papel que cada cientista teve na sua formulação, vamos relembrar de forma breve alguns outros pontos de suas principais contribuições individuais. 


\section{Carnot}

O trabalho de Carnot de 1824, muito embora tenha sido ignorado na época, hoje se constitui numa das obras primas da História das Ciências. Preocupado inicialmente com o desempenho das máquinas a vapor, Carnot sistematizou a Termodinâmica, colocando limites físicos para a transformação de energia térmica (calor) em energia mecânica (trabalho).

Além do que já discorremos, salientamos os seguintes pontos nas contribuições de Carnot, relacionados à primeira lei da Termodinâmica:

a) Nos seus estudos ele considerou como correta a Teoria do Calórico e que, assim, numa máquina a vapor, haveria conservação do calórico. Como mencionamos, Carnot descreveu o comportamento do calórico em sua máquina térmica de forma semelhante a da água que cai de uma caixa d'água e, que esta água poderia voltar à caixa por meio de uma bomba. Desse modo, sua máquina poderia trabalhar de forma reversível. $\mathrm{O}$ calórico 'cai' da fonte quente para a fria, mas ele pode ser 'elevado' da fonte fria para a quente. Apesar dessa concepção do calor ele escreveu em 1824 (ENCYCLOPAEDIA BRITANNICA, 1979; PÁDUA; PÁDUA; SILVA, 2008):

"Ninguém ignora que o calor pode ser a causa do movimento. Que ele possui até uma grande potência motriz: as máquinas a vapor, hoje tão espalhadas, são uma prova eloqüente para quem tiver olhos para ver".

b) Sobre o equivalente mecânico do calor, ele encontrou, sem justificativas, o seguinte número: 3,62 J/cal. Parece que Carnot não usou a expressão equivalente mecânico do calor.

c) Após a sua morte, em 1832, descobriu-se uma série de notas, nas quais ele mostrava que tinha abandonado a teoria do calórico e sugerido que no funcionamento de sua máquina, o que conserva era a energia e não o calor. Nestas notas ele escreveu (ENCYCLOPAEDIA BRITANNICA, 1979; PÁDUA; PÁDUA; SILVA, 2008):

"Podemos estabelecer como tese geral que a potência motriz existe em quantidade invariável na Natureza, que ela nunca é, propriamente falando, nem produzida nem destruída. Na verdade, ela muda de forma, isto é, ela produz umas vezes um tipo de movimento outras vezes um tipo diferente, mas nunca é destruída. Este princípio deduz-se por si só, digamos assim, da teoria mecânica".

Nos meandros desta frase, Carnot mostra claramente que havia esboçado uma lei da conservação da energia, a possibilidade de transformações recíprocas das diferentes formas de energia e que se antecipara o a Mayer, Joule e Helmholtz, na formulação da primeira lei.

\section{Mayer}

Entre os anos de 1842 e 1843, os trabalhos teóricos de Mayer introduziram claramente a noção de equivalência entre calor e trabalho e, elevou o princípio da conservação de energia à condição de lei, aplicável a todos os fenômenos térmicos.

Em 1842, formulou claramente a primeira lei da seguinte forma (BEN-DOV, 1995; ENCYCLOPAEDIA BRITANNICA, 1979; PÁDUA; PÁDUA; SILVA, 2008):

"Quando um sistema material apenas troca trabalho mecânico e calor com o exterior, e volta em seguida ao seu estado inicial ocorre que: se o sistema recebeu trabalho, cedeu calor e se o sistema recebeu calor, forneceu trabalho; há uma razão constante entre o trabalho (W) e a quantidade de calor (Q) trocado: W/Q 
$=$ constante $=\mathrm{J}$, em que $\mathrm{J}$ é designado por equivalente mecânico do calor".

Mayer encontrou o valor de 3,56 J/cal para a constante J. Especula-se que se ele tivesse usado os dados atuais ele teria chegado em 4,184.

Joule

O impulso definitivo para o estabelecimento do equivalente mecânico do calor foi dado por meio das experiências de James Joule entre os anos 1843 e 1845. Estas evidenciaram a proporcionalidade entre o desprendimento de calor e o trabalho fornecido, resultando daí uma definição precisa de equivalente mecânico do calor. Entre seus feitos podemos citar também:

a) Em 1843, convenceu os cépticos de que o calor não era uma substância, descartando de certa forma, a teoria do calórico e conduzindo a teoria mecânica do calor.

b) A partir de uma série de experiências, chegou à mesma conclusão de Mayer, e encontrou o seguinte resultado: $\mathrm{J}=4,154 \mathrm{~J} / \mathrm{cal}$.

c) Concluiu que a energia potencial podia transformar-se em energia cinética e a energia cinética podia transformar-se em calor. $\mathrm{O}$ calor e a energia mecânica podem, portanto, ser consideradas como manifestações diferentes da mesma quantidade física: a energia.

\section{Helmholtz}

O conceito de energia, presente em todos os desenvolvimentos da Mecânica Clássica, recebeu por parte de Helmholtz uma aplicação geral, ou seja, se um corpo possui energia mecânica caso possa produzir trabalho, então os fenômenos do calor, da eletricidade e das combinações químicas podem ser, também, associados à produção de trabalho.
Partindo disso, Helmholtz pôde enunciar o princípio de que se, em um sistema isolado, desaparece um certo trabalho ou um equivalente de trabalho, pertencente a diversas formas de energia, a mesma energia deve aparecer sob outras formas. Esta formulação geral do princípio da conservação da energia, aplicada a todos os fenômenos conhecidos, tais como mecânicos, elétricos, magnéticos, térmicos, químicos e biológicos, foi apresentada por ele à Sociedade de Física de Berlim, em 23 de julho de 1847.

Em seu livro "Sobre a Conservação da Energia" [usa ainda a palavra força em vez de energia e força viva em vez de energia cinética] ele diz o seguinte (BEN-DOV, 1995; ENCYCLOPAEDIA BRITANNICA, 1979; PÁDUA; PÁDUA; SILVA, 2008):

“... chegamos à conclusão de que a natureza como um todo possui um estoque de energia que não pode de forma alguma ser aumentado ou reduzido; e que, por conseguinte, a quantidade de energia na natureza é tão eterna e inalterável como a quantidade de matéria. Expressa desta forma, chamei esta lei geral de Princípio da Conservação da Energia."

\section{Clausius}

As contribuições de Clausius para a sistematização da Termodinâmica foram realmente muito significativas. Por esta razão, vamos minudenciar um pouco mais suas idéias sobre a primeira lei.

Em 1850, faz sua primeira grande publicação a respeito da teoria do calor. Neste trabalho, Clausius estabeleceu os fundamentos da Termodinâmica moderna.

Clausius apresentou argumentos rejeitando a teoria do calórico em favor de um princípio que 
estabelecia a equivalência entre o trabalho e o calor.

$\mathrm{Na}$ época, a teoria do calórico tinha duas suposições centrais: (I) o calor presente num sistema físico (um corpo ou substância qualquer) era uma função de estado deste sistema e (II) o calor total do universo era conservado.

O estado macroscópico de um sistema termodinâmico simples fechado pode ser definido pelas variáveis T, P e V. A cada duas destas variáveis geram uma função de estado deste sistema. Por exemplo, Poisson, estabeleceu uma relação entre $\mathrm{P}$ e $\mathrm{V}$ numa expansão adiabática de gases e Clapeyron determinou a variação de $\mathrm{P}$ e $\mathrm{T}$ durante uma expansão isocórica. Do mesmo modo, outras propriedades do sistema podiam ser determinadas definindo-se funções de estado passíveis de serem tratadas matematicamente. Assim, para Clausius, a suposição (I) de que o calor presente em uma substância era uma função de estado daquela substância, transformava a teoria do calórico de uma vaga suposição sobre um fluido imponderável, em um sofisticado sistema matemático onde relações permanentemente válidas, poderiam ser obtidas.

Clausius fez uma análise cuidadosa sobre a natureza do calor, colaborando de forma efetiva para o estabelecimento formal da primeira lei da Termodinâmica e, conseqüentemente, descartando a suposição (II) da teoria do calórico de que o calor do universo era conservado. O texto reproduzido a seguir traz uma excelente exposição delineando as principais idéias de Clausius sobre a natureza do calor (apresentado em PÁDUA; PÁDUA; SILVA, 2008).

“... A teoria do calórico também provia de uma idéia conceitual para explicar o comportamento dos gases e do vapor em termos de uma distinção entre os estados livre e latente do calor. Calor livre podia ser sentido e medido através de termômetros, enquanto o calor latente, devido ao fator de estar intimamente ligado com as ligações entre as moléculas, não poderia. Além disso, a temperatura de um gás se elevava quando ele era comprimido porque parte do seu calor latente das ligações, aparentemente era transformado em calor livre.

Clausius não somente negou as considerações fundamentais da teoria do calórico, como também construiu uma nova explicação mecânica para os tradicionais conceitos de calor latente e calor livre.

A recusa foi baseada naquilo que se tornou a primeira lei da Termodinâmica: toda vez que trabalho é produzido por meio de calor, é consumida uma quantidade de calor equivalente à quantidade de trabalho produzida. Uma premissa que Clausius acreditava ter sido firmemente estabelecida por meio dos experimentos de Joule.

O total de calor no universo, então não poderia ser conservado; e o conceito usual de calor em uma substância, representando o total de calor adicionado para aquela substância, não poderia ser considerado mais como uma função de estado.

Em sua re-interpretação, a única forma de calor que poderia haver em qualquer condição real em uma substância era o calor livre; e o calor livre era entendido como a vis viva (energia cinética) das particulas fundamentais da matéria $e$ determinada pela temperatura. O calor latente, em contraste, era o calor que não mais existia, tendo sido destruido pela conversão em trabalho interno contra forças inter moleculares $e$ trabalho externo contra a pressão da vizinhança. Clausius fez uma importante distinção entre as duas formas de trabalho. O trabalho interno que é determinado pela configuração molecular, é uma função de estado, sujeita somente às condições iniciais e finais da mudança e o trabalho externo, que depende das condições sob as quais a mudança ocorre.

Em 1850, Clausius não deu as expressões 
matemáticas para essas idéias interpretativas do calor de um corpo e trabalho interno, mas simplesmente ilustrou-os com uma explanação sobre a vaporização da água; eles formaram, entretanto, as idéias conceituais de sua teoria do calor. Mesmo no final da edição de um trabalho que apareceu em 1887, ele ainda apresentou a primeira lei da Termodinâmica como $\mathrm{dQ}=\mathrm{dH}+\mathrm{dJ}+\mathrm{dW}$, onde o incremento de calor dQ adicionado a um corpo é igual à soma de mudanças de calor do corpo $\mathrm{dH}, o$ trabalho interno dJ e o trabalho externo dW. Somente depois de confessar sua ignorância sobre a expressão do trabalho interno dJ, Clausius apresentou a expressão clássica da Termodinâmica $\mathrm{dQ}=\mathrm{dU}+\mathrm{dW}$, onde $\mathrm{U}$ era simplesmente energia no corpo, sem qualquer tentativa de diferenciar a energia em formas moleculares. A função U representou uma importante contribuição na nova teoria mecânica do calor, e foi Clausius que apresentou esta nova propriedade de estado no pensamento termodinâmico. Esta foi uma outra importante contribuição de sua publicação de 1850.

A maneira de Clausius estabelecer a função $\mathrm{U}$ como uma propriedade de estado de uma substância revela outra característica distinta de seu pensamento. Em sua abordagem da teoria do calor, conceitos gerais não deveriam ser dependentes de modelos particulares, porque aqueles muitos conceitos formam a estrutura onde os modelos deveriam funcionar. Embora Clausius pudesse apresentar a função $\mathrm{U}$ simplesmente como soma de $\mathrm{H}$ e $\mathrm{J}$ (como ele fez posteriormente no desenvolvimento de sua teoria), ele preferiu ter certeza de uma completa generalidade de suas idéias iniciais de 1850, empregando uma análise extremamente tediosa de um Ciclo de Carnot infinitesimal. Era como se fosse uma abordagem, independentemente das considerações moleculares, que se tornou normativa no pensamento termodinâmico.
Por exemplo, quando Kelvin desenvolveu sua teoria dinâmica do calor em 1851, ele não explicou a função U em termos dos estados de energia molecular. Ele simplesmente argumentou que se $\mathrm{Q}$ e $\mathrm{W}$ devem ser iguais toda vez que uma substância percorrer um ciclo completo de mudanças, uma conseqüência do teorema da equivalência do trabalho e calor, e se cada função, que é característica de uma substância, não mostra nenhuma mudança resultante em um ciclo, Q-W deve representar alguma função da substância. Então, ele adotou a questão puramente em um nível macroscópico e deu o nome de "energia intrínseca" para $\mathrm{U}$.

Clausius tinha descoberto a função U um ano antes de Kelvin, mas ele nunca tinha dado um nome para ela. A razão é clara: o calor em um corpo $\mathrm{H}$ eo trabalho interno J eram seus conceitos fundamentais. Por exemplo, a fim de simplificar a função U para gases e obter a equação de Poisson para o comportamento adiabático dos gases, ele argumentou que as forças intermoleculares são desprezíveis em gases por causa de sua relativa uniformidade de suas relações de pressão, volume e temperatura. Ele estava apto para reduzir a função U para o calor absorvido em volume constante e demonstrou que esse calor podia depender somente da temperatura. Uma simplificação da função U normalmente requer o uso da segunda lei da Termodinâmica, mas Clausius originalmente propôs a idéia somente baseada na primeira lei e em seu modelo molecular para calor e trabalho interno. Aquele modelo para o calor talvez tenha também possibilitado o raciocínio para sua brilhante revisão do tradicional argumento de Carnot em Termodinâmica. Uma revisão que possibilitou incorporar a maioria dos resultados significativos da teoria do calórico com a nova estrutura teórica. ..." 
A figura 6 ilustra o critério proposto por Clausius para a troca de trabalho (W) e calor (Q) em um sistema termodinâmico fechado com a sua vizinhança.

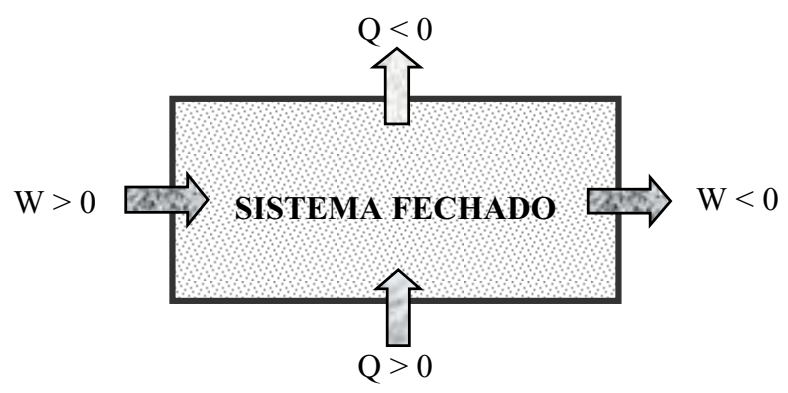

Figura 6. Convenção para troca de trabalho e calor em um sistema com a sua vizinhança proposta por Clausius.

Para concluirmos este assunto, apresentamos um enunciado formal atualizado para a primeira lei da Termodinâmica e alguns comentários adicionais correlacionados (CALLEN, 1995; MORSE, 1969; NUSSENZVEIG, 1981; PÁDUA; PÁDUA, 2006; SMITH; VAN NESS; ABBOTT, 2000; SOMMERFELD, 1964; SONNTAG; BORGNAKKE; VAN WYLEN, 1998; TIPLER, 2000).

"Todo sistema termodinâmico possui, em um estado de equilíbrio, um parâmetro(ou variável) extensivo de estado, chamado energia interna $\mathrm{U}$, cuja variação dU em um processo diferencial é dada pela expressão: $\mathrm{dU}=\mathrm{AQ}+\mathrm{dW}_{\mathrm{M}} \cdot "$

\section{Comentários:}

a) $\mathrm{dQ}=$ uma quantidade infinitesimal de calor absorvido pelo sistema.

b) $\mathrm{AW}_{\mathrm{M}}=$ uma quantidade infinitesimal de trabalho realizado sobre o sistema pela sua vizinhança.

c) W e Q não são parâmetros (variáveis) extensivos de estado do sistema, isto é, não dependem dos valores dos parâmetros que caracterizam o sistema.
Logo, $\mathrm{dQ}$ e $\mathrm{AW}_{\mathrm{M}}$ não são diferenciais exatas. Por isto, são representadas com um corte na letra d.

d) A primeira Lei da Termodinâmica expressa o Princípio Físico da Conservação da Energia nas transformações ou processos termodinâmicos, reconhecendo o calor como uma forma de energia. Do mesmo modo que a Lei Zero traz em si, o conceito da grandeza temperatura, a primeira lei tem em sua essência o conceito de energia interna.

e) Princípio da Energia Interna Mínima: "Num sistema composto os valores atingidos pelos parâmetros termodinâmicos internos desvinculados são tais que minimizam a energia interna para um dado valor da entropia".

f) Por volta de 1860, o Princípio da Conservação da Energia, que corresponde à primeira lei da Termodinâmica, já havia sido reconhecido como um princípio fundamental, aplicável a todos fenômenos conhecidos.

\section{Segunda Lei da Termodinâmica}

Historicamente, a formulação da segunda lei esteve ligada a um problema de engenharia, surgido pouco depois da invenção da máquina a vapor. A pergunta fundamental que se fazia era a seguinte: como se poderia aumentar o rendimento de uma máquina térmica, tornando-a o mais eficiente possivel?

Os principais cientistas responsáveis diretos ou indiretospelaformulaçãodasegundaleiforam:Carnot, Clausius, Kelvin, Maxwell, Boltzmann, Gibbs, entre outros (ENCYCLOPAEDIA BRITANNICA, 1979; KONDEPUDI; PRIGOGINE, 1999; MODEL; REID, 1974; MORSE, 1969; NUSSENZVEIG, 1981; PÁDUA; PÁDUA, 2006; PÁDUA; PÁDUA; SILVA, 2008; SEGRÈ, 1980; SOMMERFELD, 1964; SONNTAG; BORGNAKKE; VAN WYLEN, 1998; TIPLER, 2000).

Vejamos como alguns deles trataram a este assunto, apresentando suas principais conclusões. 


\section{Carnot}

Em 1824 Carnot discutiu esta questão e escreveu (ENCYCLOPAEDIA BRITANNICA, 1979; PÁDUA; PÁDUA; SILVA, 2008):

"A máquina a vapor escava nossas minas, propele nossos navios, escava nossos portos e rios, forja o ferro . . Retirar hoje da Inglaterra suas máquinas a vapor seria retirar-lhe ao mesmo tempo o carvão e o ferro. Secariam todos suas fontes de riqueza . . Apesar do trabalho de toda sorte realizado pelas máquinas a vapor, não obstante o estágio satisfatório de seu desenvolvimento atual, a sua teoria é muito pouco compreendida".

Carnot percebeu que o condensador era indispensável em um processo cíclico, e que ele representava uma ineficiência intrínseca e irremovível do processo, pois nele parte do calor que a caldeira fornecia e que não se transformava em trabalho no pistão, era transferida para fora da máquina, por exemplo, para a água do rio que resfriava o condensador.

Com isso, não era possível construir uma máquina, seja a vapor ou a uma outra substância, que transformasse totalmente em trabalho (energia mecânica) uma certa quantidade de calor fornecida por uma chama ou por uma outra fonte. Parte do calor sempre sobrava e precisava ser liberada. Essa impossibilidade era uma imposição da própria natureza, que veio a ser conhecida como o Segundo Princípio ou Segunda Lei da Termodinâmica (o Primeiro Princípio estabeleceu o calor como uma forma de energia).

Notas complementares de sua obra, bem como diversos estudos realizados posteriormente, foram revelados somente depois de sua morte. Em 1878, Hippolyte, seu irmão, apresentou essas notas à Academia de Ciências. Nelas estava esboçado o segundo princípio da Termodinâmica. A comunicação, porém, veio tarde, pois a essa altura, como já mencionamos, tal princípio já havia sido formulado precisamente por Clausius (1850) e Kelvin (1851).

Em seus estudos relacionados com este princípio, Carnot concluiu também que: (a) quando dois corpos, inicialmente a temperaturas diferentes, são postos em contato, tendem a atingir a mesma temperatura e (b) quando dois corpos com temperaturas iniciais iguais são postos em contato, seus estados térmicos não evoluem espontaneamente para temperaturas diferentes, sem que seja necessário despender energia pela vizinhança.

\section{Clausius}

Com base nas idéias de Carnot, em 1850 Clausius chegou à conclusão de que o calor não podia passar espontaneamente de um corpo de menor temperatura para um outro com temperatura maior. Esclareceu muitos conceitos e deu a seguinte forma à segunda lei: É impossivel que uma máquina frigorifica que trabalhe ciclicamente transfira energia como calor, de um corpo frio para outro quente, sem que um agente externo realize trabalho. Nesta definição estão implicitamente expressas a primeira e a segunda lei.

Em 1854 introduziu o conceito de valor de equivalência de uma transformação térmica e que era medido pela relação entre a quantidade de calor e a temperatura na qual ocorria a transformação. Com este conceito, ele distinguiu os processos reversíveis dos processos irreversíveis. Na transformação em que o calor fluía do corpo quente para o frio o valor de equivalência era positivo. Em 1865 propôs o termo entropia S para substituir a denominação valor de equivalência.

Por meio de deduções matemáticas simples ele deduziu as seguintes expressões para os processos reversíveis e irreversíveis, respectivamente: 
- Para processos reversíveis: $\mathrm{dS}=\frac{\mathrm{dQ}_{\mathrm{rev}}}{\mathrm{T}} \mathrm{e}$

- Para processos irreversíveis: $\mathrm{dS}>\frac{\mathrm{dQ}_{\mathrm{irrev}}}{\mathrm{T}}$.

Estas expressões representam um desenvolvimento das idéias de Carnot e permitem concluir que:

"Em qualquer transformação que se produza num sistema isolado, a entropia do sistema aumenta ou permanece constante. Não há, portanto, qualquer sistema térmico perfeito no qual todo o calor é transformado em trabalho. Existe sempre uma determinada perda de energia".

Esta forma de exprimir a segunda lei pode ser entendida como uma síntese do resultado final dos trabalhos de Carnot e Clausius.

\section{Kelvin}

Em 1851, chegou à conclusão de que é impossível construir uma máquina que extrai calor de uma dada fonte e o transforma todo em energia mecânica sem causar alguma mudança nos corpos vizinhos.

Seu enunciado da segunda lei foi assim formulado: Nenhum processo é possível em que o único resultado seja a absorção de calor de um recipiente e a sua completa conversão em trabalho.

Ratificando o que já colocamos, foi Clausius, em 1850 e Kelvin em 1851, que efetivamente enunciaram a segunda lei de uma forma mais precisa.

Para concluir este tópico, apresentamos a seguir uma síntese dos enunciados alternativos e equivalentes da segunda lei da Termodinâmica na forma que são apresentados atualmente nos livros didáticos, tecendo também, alguns comentários finais que lhes são pertinentes (CALLEN, 1985; KONDEPUDI; PRIGOGINE, 1999; MODEL; REID, 1974; MORSE, 1969; NUSSENZVEIG, 1981; PÁDUA; PÁDUA, 2006; SOMMERFELD, 1964; SONNTAG; BORGNAKKE; VAN WYLEN, 1998; TIPLER, 2000).

\section{Enunciado de Kelvin}

"É impossível remover energia térmica de um sistema a uma temperatura constante e converter esta energia em trabalho mecânico sem provocar uma outra alteração no sistema ou nas vizinhanças do sistema".

\section{Enunciado de Kelvin - Planck (máquina térmica)}

"É impossível que uma máquina térmica, operando em ciclo, remova calor do reservatório quente e o converta completamente em trabalho sem provocar outros efeitos".

\section{Enunciado de Clausius}

"É impossível um processo cujo único efeito seja a transferência de calor de um corpo frio para outro mais quente".

Enunciado de Clausius (refrigerador)

"É impossível que um refrigerador, operando em ciclo, provoque exclusivamente o efeito de transferir energia térmica de um corpo frio para um outro corpo mais quente".

\section{Enunciado da entropia}

"Em qualquer processo, a entropia do universo (isto é, do sistema mais as suas vizinhanças) não diminui: não é afetada por processos reversíveis e cresce em processos irreversíveis". 


\section{Comentários:}

a) O princípio do aumento da entropia é equivalente à segunda lei da Termodinâmica.

b) De forma absolutamente sintética, podemos dizer que a segunda lei traz em si um Princípio de Evolução, que de certa forma traduz o caráter irreversível dos processos naturais. Estes fenômenos 'seguem' o sentido da 'flecha do tempo' como dizia Arthur Eddington.

c) Clausius propôs, em 1865, uma formulação teórica para um ciclo reversível qualquer, construindo-o a partir de uma sucessão de Ciclos de Carnot. É com base nesta construção que ele introduziu o conceito da variável termodinâmica entropia.

d) Princípio da Entropia Máxima: "Para um dado valor da energia interna total de um sistema composto, os valores das grandezas termodinâmicas internas desvinculadas no equilíbrio, são tais que maximizam a entropia".

e) Uma outra forma mais geral da segunda lei: " $A$ entropia do universo tende a um valor máximo".

f) A validade da segunda lei da Termodinâmica é uma negação da existência de máquinas e refrigeradores ideais ou perfeitos.

g) Por fim, podemos dizer também que a segunda lei expressa a relação entre a entropia e a espontaneidade de uma transformação termodinâmica.

\section{Conclusões gerais}

Se tomarmos a máquina a vapor como nossa referência central para discorrermos acerca da Termodinâmica, podemos dizer que a origem de sua história se encontra entre os séculos XII e XVI. Neste período ocorreu uma destruição quase que total das florestas inglesas, pois a lenha foi usada de forma desmedida para aquecer as casas no inverno e, também, nas indústrias que começavam a serem implantadas. No século XVII, como já não havia mais lenha suficiente, os ingleses recorreram então, ao carvão de pedra.
As minas de carvão na época eram superficiais. No entanto, com o esgotamento deste combustível próximo à superfície do solo, começaram a abrir buracos e galerias cada vez mais profundas para encontrá-lo. Essas minas freqüentemente ficavam inundadas de água devido aos lençóis subterrâneos. Assim, tornou-se necessário bombear essa água para fora, para que pudesse extrair o carvão. Aqui começa um importante capítulo da Física, a partir da invenção da máquina a vapor. Esta foi concebida inicialmente com um fim bem específico: bombear a água para esvaziar as minas de carvão subterrâneas.

Por mais de dois séculos, a Mecânica Newtoniana foi considerada o exemplo por excelência de uma ciência exata. Descartes preconizava que para estudarmos um sistema físico devíamos decompô-lo em seus constituintes materiais e depois determinar o movimento de cada um deles.

O século XIX viu surgir, no entanto, por meio dos estudos dos fenômenos ligados ao calor, entidade primordial na máquina a vapor, uma nova abordagem científica fundada em princípios gerais que permitiam estudar os sistemas físicos em sua totalidade. Esta foi a Termodinâmica, que significava originariamente 'movimento do calor'.

A Termodinâmica caracteriza-se por uma assimetria fundamental nos processos de ocorrência dos fenômenos físicos: ela autoriza determinado processo, mas proíbe o processo inverso. Por exemplo, o calor flui espontaneamente do corpo quente para o corpo frio e não ao contrário.

A história da formulação dos dois princípios básicos da Termodinâmica é uma das mais curiosas. Nasceu no meio de questões tecnológicas e adquiriu rapidamente um caráter cosmológico. A forma mais geral com que os dois princípios foram reformulados por Rudolf Clausius no ano 1865, apenas recordando-os, "A energia do universo é constante" e "A entropia do universo se aproxima de um máximo", é uma testemunha inconteste disso. 
Considera-se hoje que esta foi a primeira formulação evolucionária da Cosmologia.

As leis da Termodinâmica que foram derivadas de generalizações de observações são em grande parte independentes de quaisquer hipóteses relativas à natureza microscópica da matéria. No entanto, é perfeitamente concebível que, mais para frente, obtenha- se uma nova informação experimental que leve à necessidade de revisão ou de reformulação dos postulados da Termodinâmica, da mesma maneira que as Leis de Newton se tornaram inadequadas para descreverem os movimentos das partículas elementares do átomo e de partículas com velocidades muito altas próximas à velocidade da luz.

A Ciência certamente não tem nenhuma formulação final. Ela está se movendo para longe de uma representação geométrica estática, em direção a uma descrição na qual a evolução e a história desempenham papéis essenciais. Para esta nova descrição da natureza, a Termodinâmica ainda é básica. Esta é nossa final mensagem ao leitor (KONDEPUDI; PRIGOGINE, 1999).

\section{Referências}

BEN-DOV, Y. Convite à fisica. Rio de Janeiro: Jorge Zahar, 1995.

CALLEN, H. B. Thermodynamics and an Introduction to thermostatistics. New York: John Wiley \& Sons, 1985.

ENCYCLOPAEDIA BRITANNICA. USA: International Copyright Union, 1979.

KONDEPUDI, D.; PRIGOGINE, I. Modern thermodynamics, New York: John Wiley \& Sons, 1999.

MODELL, M.; REID, R. C. Thermodynamics and its applications. New Jersey: Prendice-Hall, 1974.

MORSE, P. M. Thermal physics. New York: W. A. Benjamin, 1969.

NUSSENZVEIG, H. M. Curso de física básica: fluidos, oscilações, ondas e calor. 2. ed. São Paulo: Edgard Blücher, 1981. v. 2.

PÁDUA, A. B.; PADUA, C. G. Termodinâmica: uma coletânea de problemas. São Paulo: Livraria da Física, 2006.

PÁDUA, A. B.; PÁDUA, C. G.; SILVA, J. L. C. A história da termodinâmica, uma ciência fundamental. Londrina: EDUEL, 2008.

SEGRÈ, E. Dos Raios X aos Quarks. Brasília: Ed. da UnB, 1980.

SMITH, J. M.; VAN NESS, H. C.; ABBOTT, M. M. Introdução à termodinâmica da engenharia química. 5.ed. Rio de Janeiro: Livros Técnicos e Científicos, 2000 .

SOMMERFELD, A. Thermodynamics and statistical mechanics. New York: Academic Press, 1964.

SONNTAG, R. E.; BORGNAKKE, C.; VAN WYLEN, G. J. Fundamentals of thermodynamics. 5. ed. New York: John Wiley \& Sons, 1998.

TIPLER, P. A. Física: mecânica, oscilações e ondas, termodinâmica. 4. ed. Rio de Janeiro: Guanabara Dois, 2000. v. 1. 
